\title{
El acceso de terceros a las redes de electricidad. un nuevo horizonte para productores y autoconsumidores ${ }^{(*)}$
}

\author{
Alejandro D. Leiva López \\ Doctor en Derecho. Investigador postdoctoral \\ Área de Derecho Administrativo \\ Universidad de Almería
}

SUMARIO:

I. INTRODUGGIÓN. II. EL ACGESO DE TERCEROS A LAS REDES

DE ELECTRICIDAD (ATR). 1. Concepto y fundamento del ATR. 2. Tipologías de redes. III. EL PROCEDIMIENTO PARA EL ACGESO Y CONEXIÓN A LAS REDES DE ELECTRICIDAD EN UN NUEVO HORIZONTE NORMATIVO. EN PARTICULAR: CONDICIONES PARA PRODUCTORES Y AUTOCONSUMIDORES. 1. Marco normativo. 2. Agentes implicados. 3. Novedades para productores. A. Caducidad de los derechos de acceso y conexión y su eventual renovación. B. Presentación de garantía económica. C. El Interlocutor Único de Posición (IUP). 4. Novedades para autoconsumidores. A. Cuestiones introductorias. B. Exención de la obligación de obtener los permisos de acceso y conexión. C. Procedimiento abreviado de conexión de instalaciones. D. El autoconsumo colectivo. E. El registro autonómico para autoconsumidores. IV. CONCLUSIONES. V. BIBLIOGRAFÍA.

RESUMEN: La red eléctrica aparece como un elemento clave, un recurso esencial, sobre el que se desarrolla un mercado eléctrico competitivo y sin barreras de entrada. Así pues, la configuración de condiciones de acceso de terceros a las infraestructuras de red sobre la base de los principios de transparencia y no discriminación contribuirá a la necesaria apertura del mercado eléctrico. En el actual escenario energético, y especialmente en relación al horizonte 2030, la regulación de las redes debe asumir importantes retos para lograr acomodar las distintas tecnologías,

\footnotetext{
* Este trabajo ha sido realizado en el marco del Proyecto de Investigación "Sostenibilidad energética y entes locales: incidencia del nuevo paquete energético de la Unión Europea" (DER2017-86637-C32-P), Ministerio de Economía y Competitividad, Programa Estatal de Fomento de la Investigación Científica y Técnica de Excelencia, Subprograma Estatal de Generación del Conocimiento, Convocatoria 2017.

Recibido: 29/08/2018.

Aceptado: 9/11/2018.
} 
en condiciones de transparencia e igualdad, y garantizar la seguridad del suministro eléctrico. En el presente trabajo examinamos las principales propuestas de revisión normativa que el ejecutivo ha esbozado, después de varios intentos fallidos desde el año 2000, en materia de acceso y conexión a las redes. En particular, vemos las novedades previstas para generadores y autoconsumidores que quieren conectar sus instalaciones a la red.

PALABRAS CLAVE: Acceso de Terceros a las Redes en el sector eléctricoproducción de electricidad - autoconsumo de energía eléctrica - transporte y distribución de electricidad

ABSTRACT: The electricity network is a key piece, an essential resource, for developing a competitive electricity market without barriers to entry. Therefore, the third-party access rules, based on the principles of transparency and non-discrimination, will contribute to all the benefits of the opening of the electricity market. In the current energy scenario, especially with regards to the 2030 horizon, the legal framework of electricity networks must assume important challenges to make room for all technologies, on the basis of transparency and equal treatment criteria, and guarantee the electricity supply. In this paper, we examine the current governmental proposals, after several failed attempts since the year 2000, for a review of the regulatory framework for third-party access in the electricity sector. In particular, we see the regulatory changes for the generators and self-consumers who want access to the national electricity grid.

KEYWORDS: Third Party Access in the Electricity Sector - Electricity generation - Electricity self consumption - Electricity transmission and distribution

\section{INTRODUGGIÓN}

Hasta principios de los años 90, el Estado interviene en casi todos los sectores de la economía a través del denominado sector empresarial público, existiendo un dominio estatal absoluto sobre los distintos elementos que integran el servicio (planificación, inversión, tarifas, optimización, explotación...). Pero es a partir de esta década cuando acontece una oleada de privatizaciones, y con ello una reestructuración del sector empresarial público, que pretende mejorar la eficiencia de las empresas y contribuir a un mayor dinamismo de la economía nacional. Estas medidas también serán adoptadas por países europeos con un mayor grado de intervencionismo público empresarial (Portugal, Grecia, Italia, Francia, Irlanda, Dinamarca y Alemania) ${ }^{1}$.

1 ARIÑO ORTIZ, G., "Empresa pública versus regulación económica", en G. ARIÑO ORTIZ, I. DEL GUAYO CASTIELLA y J. M. DE LA GUÉTARA MARTÍNEZ (coords.), Regulación Económica. Lecturas Escogidas, Ed. Thomson Reuters Aranzadi, Cizur Menor, 2012, pp.17-20. 
Específicamente, en el sector eléctrico se trataban de corregir los fallos de mercado promoviendo la competencia en aquellas actividades donde fuese posible (producción y comercialización) y regulando la actuación empresarial desarrollada en la actividad no competitiva o de monopolio natural (transporte y distribución).

Paralelamente, la Directiva 1996/92/CE del Parlamento Europeo y del Consejo, de 19 de diciembre, sobre normas comunes para el mercado interior de la electricidad $^{2}$ comenzaba a definir los principios de la liberalización del sector eléctrico para Europa.

Se va evolucionando de un esquema de organización industrial intervenido a un modelo basado en la libre competencia y en la libertad de empresa, donde el reconocimiento de la autonomía empresarial va a perseguir una más eficiente asignación de recursos y la innovación y calidad en el suministro de electricidad, entendido este último como un servicio esencial para la economía y la sociedad. Todo ello bajo la supervisión de determinadas actuaciones por parte del gobierno cuando las condiciones medioambientales y de seguridad y continuidad del suministro así lo exijan ${ }^{3}$.

Aparece, así, un nuevo modelo eléctrico que convierte a la red eléctrica en un elemento clave sobre el que se desarrolla el mercado eléctrico. Las redes de transporte y distribución de electricidad constituyen el soporte físico a través del cual se pone en contacto la oferta y la demanda, por lo que su adecuada regulación y control es esencial para la configuración de condiciones de acceso a sus infraestructuras transparentes y no discriminatorias que eviten eventuales conflictos de interés y falseamientos de mercado. Por tanto, se va a reconocer a los distintos operadores un derecho de acceso o uso de las redes de un tercero, lo cual es condición indispensable para la formación de un mercado competitivo ${ }^{4}$.

Así pues, el presente trabajo tiene por objeto, de un lado, abordar algunos aspectos conceptuales que pivotan en torno al acceso de terceros a las redes de transporte y distribución de electricidad y, de otro, examinar las especificidades de un procedimiento de acceso y conexión a las redes que debe armonizar con la evolución propia del sector.

En este último punto, analizamos los cambios normativos que el gobierno tiene encima de la mesa y, específicamente, hemos centrado el objeto de estudio en el ac-

2 DOCE núm. 027, de 30 de enero de 1997.

3 DE LA CRUZ FERRER, J. "El debate sobre el régimen jurídico del tendido de redes de distribución y de su acceso y conexión a otras redes", en Revista de derecho de las telecomunicaciones e infraestructuras en red, núm. 20 (2004), pp.136-137.

4 ESTOA PÉREZ, A., "Acceso a redes de energía eléctrica, resolución de conflictos y evolución normativa en la materia", en Revista General de Derecho Administrativo, núm. 43 (2016), p. 2. 
ceso de productores y autoconsumidores a las redes de electricidad. Se trata de una revisión regulatoria que era necesario acometer en el sector para poder cumplir con las expectativas de desarrollo de un modelo de generación distribuida adecuado, favorecer el crecimiento de la generación de origen renovable en el horizonte 2030 e integrar toda la normativa dispersa existente en la materia. Y es que esta revisión regulatoria es imprescindible para lograr acomodar las distintas tecnologías en condiciones de igualdad y transparencia para todos los agentes, así como para garantizar la seguridad del sistema en su conjunto.

Vemos, así, cómo van surgiendo retos que el sector debe ser capaz de afrontar para lograr una transición energética que camine firmemente hacia un modelo descarbonizado.

\section{EL AGCESO DE TERGEROS A LAS REDES DE ELEGTRICIDAD (ATR)}

\section{Concepto y fundamento del ATR}

La existencia de condiciones de acceso a las infraestructuras de red transparentes y no discriminatorias, como piedra angular de la liberalización del sector eléctri$\mathrm{Co}^{5}$, requiere de la configuración de un derecho universal de acceso de los distintos agentes a las redes ajenas; esto es, el denominado Acceso de Terceros a la Red (en adelante, ATR), el cual aparece como una autorización dirigida a los distintos agentes para poder trasladar la electricidad por las redes cuya titularidad ostentan otros agentes. Se suprimen, por tanto, los derechos de exclusiva que, en un espacio temporal anterior, permitían a los propietarios de las redes poner trabas al acceso a sus infraestructuras.

El fundamento del ATR lo localizamos en la doctrina anglosajona de los recursos esenciales (essential facilities) ${ }^{6}$. Así, el derecho de acceso aparece como un instrumento liberalizador que permite a una empresa acceder a un determinado recurso o activo empresarial que es controlado por otra empresa, sin el cual devendría imposible la oferta de bienes o servicios en un mercado determinado. De forma que

5 Como así es definido por la propia Comisión Nacional de los Mercados y la Competencia. El fundamento de ello radica en que la apertura efectiva del mercado eléctrico, como objetivo central del proceso liberalizador, va a depender de una disponibilidad real de las redes de transporte y distribución existentes en condiciones de transparencia y no discriminación. El libre acceso a las redes aparece, por tanto, como piedra angular de este sector económico estratégico. Véase CATR 22/2008 (resolución del conflicto de acceso a la red de distribución instado por un particular frente a Endesa Distribución Eléctrica), p. 8.

6 A su vez esta doctrina proviene del «Antitrust Law» norteamericano, con origen en la Ley Federal antimonopolios de 1890 (Ley Sherman). 
si se rechaza el acceso injustificadamente, se estaría eliminando la competitividad en el mercado y se obstaculizaría la entrada de nuevos productos ${ }^{7}$.

En el caso del sector eléctrico, este recurso esencial es la red eléctrica, la cual es explotada por sus titulares en régimen de monopolio natural. De manera que el libre acceso a estas infraestructuras servirá de contrapunto al carácter monopolista de las redes y contribuirá a la necesaria apertura del mercado eléctrico.

Destacadamente, nos encontramos con un escenario energético donde las últimas subastas de renovables para la asignación de un régimen retributivo específico lanzan importantes retos regulatorios sobre las redes de electricidad. Una primera subasta celebrada en enero de 2016 donde se adjudicaron $700 \mathrm{MW}$ para biomasa y eólica ${ }^{8}$, la siguiente que tuvo lugar en mayo de 2017 de 3.000 MW para fotovoltaica, eólica y otras tecnologías ubicadas en el sistema peninsular ${ }^{9} \mathrm{y}$, por último, la de julio de 2017 de 5.036,921 MW para fotovoltaica y eólica ${ }^{10}$. Como resultado de las subastas se va a obtener la potencia adjudicada a cada empresa participante para cada tecnología, para lo que se utilizará el método de sobre cerrado con sistema marginal ${ }^{11}$.

Por tanto, la configuración de unas condiciones de uso de las infraestructuras de red transparentes y no discriminatorias es determinante para el cumplimiento de

7 DIATHESOPOUlOS, M. D., "Access to European Energy Networks: The Relation between Third Party Access and Refusal to Deal Concepts", en Social Science Research Network (posted: 02 Jan 201 1), p. 8.

8 Resolución de 18 de enero de 2016, de la Dirección General de Política Energética y Minas, por la que se resuelve la subasta para la asignación del régimen retributivo específico a nuevas instalaciones de producción de energía eléctrica a partir de biomasa en el sistema eléctrico peninsular y par instalaciones de tecnología eólica, al amparo de lo dispuesto en el Real Decreto 947/2015, de 16 de octubre. BOE núm. 18, de 21 de enero de 2016.

9 Resolución de 19 de mayo de 2017, de la Dirección General de Política Energética y Minas, por la que se resuelve el procedimiento de subasta para la asignación del régimen retributivo específico al amparo de lo dispuesto en el Real Decreto 359/2017, de 31 de marzo, y en la Orden ETU/315/2017, de 6 de abril. BOE núm. 125, de 26 de mayo de 2017. En esta convocatorio se subastó un cupo de 2.000 MW de potencia renovable que podría ampliarse en otros 1.000 MW adicionales si el resultado de la subasta ofrecía precios competitivos, como finalmente sucedió.

10 Resolución de 27 de julio de 2017, de la Dirección General de Política Energética y Minas, por la que se resuelve el procedimiento de subasta para la asignación del régimen retributivo específico al amparo de lo dispuesto en el Real Decreto 650/2017, de 16 de junio, y en la Orden ETU/615/2017, de 27 de junio. BOE núm. 179, de 28 de julio de 2017. En esta convocatoria asignaba un máximo de 3.000 MW, pero, de conformidad con lo dispuesto en el Real Decreto 650/2017, de 16 de junio, éste podría verse incrementado para permitir la inclusión de la potencia de todas aquellas ofertas que tuviesen el mismo sobrecoste que la última oferta adjudicada, y siempre que este sobrecoste para el sistema sea nulo o inferior al valor establecido en la cláusula confidencial de la convocatoria. Finalmente se adjudicaron más de $5.000 \mathrm{MW}$.

11 MENDOZA LOSANA, A. I., "Régimen retributivo de las instalaciones de energías renovables tras la celebración de las últimas subastas de potencia renovable en España”, en Análisis jurídicos GA $E^{2} P$, (2017), Gómez-Acebo \& Pombo, p. 8. 
los plazos de esta nueva potencia renovable (más de $8.000 \mathrm{MW}$ ) que entra al sistema con ocasión de las subastas.

\section{Tipologías de redes}

Las infraestructuras sobre las que se proyecta este principio del ATR son las denominadas redes de transporte y redes de distribución de electricidad.

La red de transporte de electricidad, de conformidad con lo dispuesto en el artículo 34 de la Ley 24/2013, de 26 de diciembre, del Sector Eléctrico (en adelante, LSE $)^{12}$, está integrada por la red primaria y la red secundaria. La red primaria está integrada por todas las líneas de electricidad, e instalaciones relacionadas (parques, transformadores y otros elementos eléctricos), que presentan una tensión nominal de $380 \mathrm{kV}$ o más, así como instalaciones que sean necesarias para cualquier conexión internacional con la red o que requieran de conexiones del sistema eléctrico peninsular con sistemas extrapeninsulares o insulares. Por otro lado, la red secundaria se refiere a todas las líneas de electricidad, e instalaciones relacionadas, que tengan una tensión nominal de 220 kV o más, y que no estén incluidas en la red primaria, así como otras instalaciones con tensión nominal inferior a $220 \mathrm{kV}$ que cumplan funciones de transporte. La titularidad y gestión de la red de transporte la ostenta con carácter general la empresa Red Eléctrica de España S.A. ${ }^{13}$, en calidad de Transportista Único, aunque cabe la posibilidad de que una empresa distinta (el distribuidor de la zona) controle infraestructura de red de transporte secundario ${ }^{14}$. La gestión de estas redes persigue garantizar la seguridad y continuidad del suministro eléctrico en todo momento.

De otro lado, el artículo 38 LSE se refiere a la red de distribución de electricidad como aquella formada por todas las líneas con tensión nominal inferior a $220 \mathrm{kV}$, salvo aquellas que estén integradas en la red de transporte. La titularidad y gestión

12 BOE núm. 310, de 27 de diciembre de 2013.

13 Sobre este punto vid. DEL GUAYO CASTIELLA, I., "Energy Law in Spain. Energy Networks", en M. ROGGENKAMP, C. REDGWELL, A. RØNNE, E I. DEL GUAYO CASTIELLA (eds), Energy Law In Europe (National, EU and International Regulation), Third Edition, Ed. Oxford University Press, Oxford, 2016, pp. 1010-1025.

14 Así lo prevé el apartado 2 del artículo 34, al disponer que «[...] se habilita al Ministerio de Industria, Energía y Turismo para autorizar expresa e individualizadamente, previa consulta a la Comisión Nacional de los Mercados y la Competencia y a la Comunidad Autónoma en la que radique la instalación, que determinadas instalaciones de transporte secundario, por sus características y funciones, sean titularidad del distribuidor de la zona que se determine. En estos casos, los distribuidores deberán asumir las obligaciones del transportista único relativas a la construcción, maniobra y mantenimiento de tales instalaciones de transporte». 
de las redes de distribución es atribuida a la empresa distribuidora de la zona autori$z a_{a}{ }^{15}$, la cual se encargará de distribuir la energía eléctrica a los puntos de consumo.

Son numerosas las compañías distribuidoras existentes e inscritas en el «Registro Administrativo de Distribuidores» del Ministerio para la Transición Ecológica, perteneciendo en su mayoría a los grupos energéticos dominantes (Endesa, Gas Natural Fenosa, Iberdrola, Viesgo y EDP $)^{16}$.

\section{EL PROCEDIMIENTO PARA EL ACGESO Y CONEXIÓN A LAS REDES DE ELEGTRICIDAD EN UN NUEVO HORIZONTE NORMATIVO. EN PARTICULAR: CONDICIONES PARA PRO- DUCTORES Y AUTOCONSUMIDORES}

\section{Marco normativo}

La regulación del principio de Acceso de Terceros a las Redes de electricidad, como elemento clave para el desarrollo de un mercado eléctrico liberalizado, vino impulsada por el derecho comunitario (Directivas 1996/92/CE, 2003/54/CE y 2009/72/CE).

Así, aparecen en nuestro ordenamiento jurídico los procedimientos de acceso y conexión a las redes como pieza fundamental para garantizar un ATR transparente y no discriminatorio. La Ley 54/1997, de 27 de noviembre, del Sector Eléctrico (en adelante, LSE de 1997) ${ }^{17}$ regula el procedimiento de acceso y conexión a la red de transporte (artículo 38) y a la red de distribución (artículo 42), estando ambos inspirados en el principio de acceso de terceros a las redes. Asimismo, para la configuración exhaustiva de los distintos hitos procedimentales en materia de acceso y conexión, se han ido elaborando desde entonces varias disposiciones reglamentarias, siendo las más relevantes: el Real Decreto 1955/2000, de 1 de diciembre, por el que se regulan las actividades de transporte, distribución, comercialización, suministro y procedimientos de autorización de instalaciones de energía eléctrica ${ }^{18}$ (sobre condiciones generales de acceso y conexión); el Real Decreto 1699/2011, de 18 de noviembre, por el que se regula la conexión a red de instalaciones de producción de energía eléctrica

15 A mayor abundamiento sobre el concepto de "distribuidor de la zona" véase LEIVA LÓPEZ, A. D., "La regulación de la actividad de distribución de energía eléctrica", en Revista Aragonesa de Administración Pública, núm. 51 (2018b), pp. 182-185.

16 Datos accesibles a través de los servicios web institucionales del Ministerio para la Transición Ecológica. http://www.mincotur.gob.es/energia/es-ES/Paginas/index.aspx.

17 BOE núm. 285, de 28 de noviembre de 1997.

18 BOE núm. 310, de 27 de diciembre de 2000. 
de pequeña potencia ${ }^{19}$; el Real Decreto 1047/2013, de 27 de diciembre, por el que se establece la metodología para el cálculo de la retribución de la actividad de transporte de energía eléctrica ${ }^{20}$; el Real Decreto 1048/2013, de 27 de diciembre, por el que se establece la metodología para el cálculo de la retribución de la actividad de distribución de energía eléctrica ${ }^{21}$; el Real Decreto 413/2014, de 6 de junio, por el que se regula la actividad de producción de energía eléctrica a partir de fuentes de energía renovables, cogeneración y residuos ${ }^{22}$; y el Real Decreto 900/2015, de 9 de octubre, por el que se regulan las condiciones administrativas, técnicas y económicas de las modalidades de suministro de energía eléctrica con autoconsumo y de producción con autoconsumo ${ }^{23}$.

En el año 2013 se aprueba una nueva ley para el sector, la Ley 24/2013, de 26 de diciembre, del Sector Eléctrico, a los efectos de revisar la regulación básica del sector. Específicamente, en materia de ATR viene a regular un nuevo modelo basado en permisos de acceso y conexión (artículo $33^{24}$ ). Cabe destacar que, de conformidad con lo establecido en la disposición transitoria undécima, este nuevo modelo no entrará en vigor hasta producido el desarrollo reglamentario de los criterios para la concesión de los permisos. Si bien hasta llegado ese momento seguirá siendo de aplicación la LSE de 1997 (artículos 38 y 42) y las disposiciones reglamentarias a que nos hemos referido supra.

En este contexto, parece que esta normativa reglamentaria pendiente, tras casi veinte años de espera desde la aprobación de la norma de referencia (RD 1955/2000) y después de varios intentos fallidos de real decreto (2007, 2009 y 2013), va a ver luz verde próximamente (las previsiones anunciadas por el ejecutivo son finales del mes de noviembre de 2018). Con carácter general, existe una propuesta (en adelante, propuesta RD de acceso y conexión) que persigue, por un lado, acabar con la dispersión normativa existente hasta la fecha, reducir las trabas administrativas injustificadas al acceso y conexión, reduciendo plazos y simplificando requisitos para la obtención de los derechos, y agilizar los procedimientos a través de una tramitación conjunta de las solicitudes de permisos de acceso y conexión y la determinación de un punto

19 BOE núm. 295, de 8 de diciembre de 2011.

20 BOE núm. 312, de 30 de diciembre de 2013.

21 BOE núm. 312, de 30 de diciembre de 2013.

22 BOE núm. 140, de 10 de junio de 2014.

23 BOE núm. 243, de 10 de octubre de 2015.

24 El precepto diseña con precisión los conceptos de derecho de acceso, derecho de conexión, así como de permiso de acceso y permiso de conexión. Además, define cuál va a ser la proyección del principio de acceso de terceros a las redes sobre los procedimientos para la obtención de permisos de acceso y conexión, así como quiénes van a ser los agentes encargados de otorgar estos permisos en base a criterios técnicos y económicos que deberán ser definidos reglamentariamente por el Gobierno. 
de contacto único ${ }^{25}$. Por otro, promover un acceso ordenado y eficiente a la red que proporcione una mayor eficiencia energética del sistema e impulse la cooperación y coordinación entre gestores y titulares de las distintas redes para favorecer la incorporación de las modalidades de generación distribuida y autoconsumo actuales ${ }^{26}$. Además, la propuesta de real decreto atiende diversos pronunciamientos de tribunales sobre cuestiones concretas que pivotan sobre el ATR.

A pesar de que se trata de una revisión normativa que es muy necesario adoptar, pues mejora sustancialmente la regulación anterior, todo parece indicar que deberá acometerse una nueva reforma con ocasión de la inminente aprobación del Paquete de Invierno Energético (el denominado Winter Package) ${ }^{27}$. Este paquete va a contener las principales propuestas legislativas, e iniciativas no legislativas, de la Comisión para la Unión de la Energía. En materia de redes, destacan importantes novedades en materia de códigos de red $^{28}$ y cooperación a escala de la Unión entre los gestores de las redes de transporte y distribución a través de la Red Europea de Gestores de Redes de Transporte (REGRT-E) y la entidad europea de los gestores de redes de distribución de la Unión (entidad de los GRD de la UE). Así, el papel del gestor de la red de distribución está evolucionando a consecuencia de la creciente penetración de recursos energéticos intermitentes y distribuidos en el sistema de distribución ${ }^{29}$, lo

25 Esta tramitación conjunta de permisos superaría la inversión de la secuencia acceso y conexión que existe en distribución (artículo 42.2 LSE de 1997), la cual exige del solicitante de acceso disponer previamente de punto de conexión a la red de distribución.

Asimismo, el artículo 5 de la propuesta de RD de acceso y conexión dispone que ese contacto único será el titular de la red de transporte o distribución para la cual se está solicitando el permiso de acceso y de conexión. Para aquellos casos en que el titular de la red no coincida con el gestor, aquél tendrá que remitir al éste las solicitudes, y posibles subsanaciones de éstas, para que sean objeto de análisis y valoración en el marco del procedimiento de concesión de permisos.

26 En la medida en que emerge una generación más pequeña y distribuida, donde se espera que la red de distribución proporcione importantes servicios para el sistema eléctrico en su conjunto, se hace necesaria una mayor proximidad entre las actividades de transporte y distribución; lo que debe traducirse en una mayor cooperación para el intercambio de información entre los agentes que operan estas redes. Vid. HANCHER, L. and WINTERS, M., The EU Winter Package, Briefing Paper, Allen \& Overy LLP, Amsterdam, 2017, p.12.

27 Paquete de medidas energéticas - Reglamentos y Directivas- presentado por la Comisión Europea, en fecha 30 de noviembre de 2016, bajo el eslogan «Clean energy for all Europeans» y que presumiblemente irá viendo luz verde entre finales del año 2018 y el primer semestre de 2019.

28 Algunas propuestas para la mejora de la gobernanza en el proceso de desarrollo de códigos de red pueden localizarse en LAVRIJSSEN, S. y KOHLBACHER, T., "EU Electricity Network Codes: Good Governance in a Network of Networks", en Tilburg Law and Economics Center (TILEC) Discussion Paper, núm. 2018-001, pp. 78-79.

29 Vid. YEMANE HADUSH, S. y MEEUS, L., "DSO-TSO cooperation issues and solutions for distribution grid congestion management", en Energy Policy, 2018, pp. 610-611. 
que atribuye a éste una labor de provisión de energía producida a pequeña escala de forma coordinada con los gestores de red de transporte ${ }^{30}$.

Seguidamente, vemos cuáles son las consideraciones particulares más destacadas que aborda esta propuesta de real decreto, con especial referencia a las novedades introducidas para el acceso y conexión a las redes de productores y autoconsumidores.

\section{Agentes implicados}

Los sujetos protagonistas en el procedimiento de acceso y conexión a las redes de transporte y distribución de electricidad son los agentes peticionarios, los agentes encargados de conceder los derechos de acceso y conexión y las autoridades administrativas encargadas de resolver eventuales planteamientos de conflictos de acceso y conexión a las redes.

El RD 1955/2000 se refiere a quiénes son estos agentes peticionarios que tendrán reconocido el derecho de acceso a las redes. Así, podrán solicitar acceso a la red de transporte los productores, autoproductores, distribuidores, comercializadores, agentes externos, consumidores cualificados y sujetos no nacionales autorizados capaces de llevar a cabo tránsitos de electricidad entre grandes redes (artículo 52), mientras que en relación a la red de distribución, se reconoce el derecho de acceso a productores, autoproductores, distribuidores, comercializadores, agentes externos y consumidores cualificados (artículo 60). Aunque cabe subrayar que el acceso de distribuidores a las redes de transporte y distribución de electricidad, en realidad, no existe; si bien solo podría darse en casos actualmente minoritarios en los que la distribuidora es también comercializadora, al tener aquélla menos de 100.000 clientes conectados a sus redes (artículo 12.4 LSE) ${ }^{31}$.

En este punto, la propuesta RD de acceso y conexión ha precisado aún más el marco de aplicación de la norma, aludiendo a agentes peticionarios como: los titula-

30 Vid. GERARD, H., RIVERO PUENTE, E. I. y SIX, D., "Coordination between transmission and distribution system operators in the electricity sector: A conceptual framework", en Utilities Policy, 2018, p. 41 .

31 Esta regulación del derecho de acceso de distribuidoras a las redes va a perder toda relevancia jurídica si se compara con su aplicabilidad en un escenario anterior a la reforma de 2007, con ocasión de la aprobación de la Ley 17/2007, en el que no era exigible una separación jurídica y funcional de las distribuidoras respecto de las empresas comercializadoras, lo que permitía observar gran número de empresas distribuidoras que también operaban como comercializadoras. Pero, a partir del año 2007, estos casos se convierten en minoritarios, pues el distribuidor ya no puede suministrar, salvo los casos previstos en el artículo 12.4 LSE. Por ello, lo que existe realmente es una conexión física de redes de distribución a otras redes, pero no un derecho de acceso. 
res de instalaciones de transporte y los promotores de instalaciones de generación y consumo todavía por construir.

También el RD 1955/2000 se va a referir a los agentes encargados de conceder los derechos de acceso y conexión a las redes.

En materia de acceso, el real decreto atribuye esta facultad, en transporte, al Operador del Sistema y Gestor de la Red de Transporte-REE- (artículo 53.1) y, para distribución, al Gestor de la Red de Distribución (artículo 62.1). Mientras que en materia de conexión, se atribuye, para transporte, al propietario de la red de transporte (artículo 57.1) y, para distribución, al propietario de la red de distribución (artículo 66.1). Para este último caso, lo normal es que el propietario de la red coincida con la figura del gestor, aunque cabría la posibilidad de que fuese un agente distinto, tanto en transporte (si la red sobre la que se solicita conexión es considerada de transporte secundario -artículo 34.2 LSE-) como en distribución (si se diese el caso previsto en el artículo 39.2 RD 1955/2000).

Así, los propietarios y gestores de red deberán atender ciertos criterios técnicos y económicos, que han sido objeto de pronunciamientos judiciales ${ }^{32}$, a la hora de valorar la aceptación de las solicitudes de acceso y conexión.

Destacadamente, la propuesta de RD de acceso y conexión establece, en el artículo 25, unas obligaciones de información de las capacidades existentes en cada nudo de red que deben asumir los titulares de éstas. La LSE ya contemplaba esta obligación de publicación de capacidades, pero ésta no se había desarrollado hasta llegada la propuesta de real decreto. Ello viene a satisfacer las numerosas reclamaciones de promotores de instalaciones de generación, y en particular de tecnología renovable, por los elevados costes que les suponía tramitar o buscar ubicaciones para sus instalaciones ante la falta de publicación de información sobre capacidades existentes en la red por parte del titular.

Por último, cabe destacar el papel protagonista que juegan las autoridades con competencia atribuida para la resolución de conflictos de acceso y conexión a las redes.

En materia de acceso, el RD 1955/2000 atribuye a la CNMC la competencia para resolver, a petición de cualquiera de las partes afectadas, los conflictos que se planteen en relación con el acceso a las redes de transporte (artículo 53.8), asumiendo también la competencia en materia de resolución de conflictos de acceso a la red de distribución (artículo 62.8).

32 Véase, por ejemplo, la STS (Sala $3^{\mathrm{a}}$ ) 2505/2015, de 13 de mayo de 2015 (Núm. recurso: 4318/2012). Ésta desarrolla detalladamente criterios técnicos que debe contener el estudio que lleva a cabo el gestor de la red de transporte cuando proceda a una denegación de acceso. 
En estos casos se observa un conflicto de intereses entre los aspectos liberalizadores inherentes al propio derecho de acceso y los intereses sobre gestión del sistema eléctrico y garantía de seguridad de las redes. Así, nos encontramos con interpretaciones del regulador favorables al acceso que se han visto limitadas por una normativa que ha hecho prevalecer los intereses de seguridad en la operación de las redes ${ }^{33}$. Si bien los tribunales (Audiencia Nacional y Tribunal Supremo) han venido aplicando el principio general de interpretación restrictiva de las causas de denegación de acceso; esto es, de lo que debe entenderse por falta de capacidad, a los efectos de ligar esta causa a la ausencia efectiva de seguridad, regularidad y calidad del suministro.

Si bien cabe destacar que la conflictividad se disparó tras la aprobación del régimen de incentivos para instalaciones de generación basadas en fuentes de energías renovables, a través del Real Decreto 661/2007, de 25 de mayo, por el que se regula la actividad de producción de energía eléctrica en régimen especial ${ }^{34}$, y disminuye a medida que han ido desapareciendo tales incentivos ${ }^{35}$. Esta competencia, que constituye para la CNMC un ámbito de actuación imperativo ${ }^{36}$, también es reconocida en el apartado $1^{\circ}$ del artículo 12.1.b) de la Ley 3/2013, de 4 de junio, de creación de la Comisión Nacional de los Mercados y la Competencia (en adelante, Ley de la CNMC) ${ }^{37}$, así como en los artículos 38 (transporte) y 42 (distribución) ${ }^{38}$ de la LSE de 1997.

33 ESTOA PÉREZ, A. (2016: 33-34).

34 BOE núm. 126, de 26 de mayo de 2007.

35 El análisis exhaustivo de esta casuística de conflictos suscitados desde el año 2007 puede observarse en ESTOA PÉREZ, A. (2016: 17-32).

36 Pues se trata de una intervención en controversias de la autoridad reguladora nacional cuya resolución le es atribuida por ley y es llevada a cabo en ejercicio de potestades administrativas, de conformidad con las disposiciones contenidas en la legislación básica administrativa. Si bien hay que diferenciar estas actuaciones de carácter público de la GNMC de aquellas en las que interviene como árbitro (artículo 5.1.b. Ley de la CNMC en remisión a la Ley 60/2003, de 23 de diciembre, de Arbitraje) a instancia de empresas energéticas y para resolver disputas entre éstas, y que, por tanto, no presentan carácter público. Vid. DEL GUAYO CASTIELLA, I. (2016), "La Comisión Nacional de los Mercados y la Competencia y la resolución de conflictos en el sector energético", en F. LÓPEZ RAMÓN (coord.), Las vías administrativas de recurso a debate, Ed. INAP, Madrid, 2016, pp. 566-567.

37 BOE núm. 134, de 5 de junio de 2013.

38 Este precepto fue modificado, en 2007, para invertir la secuencia acceso y conexión en distribución, de manera que a partir de ese momento para poder solicitar el acceso a la red de distribución era necesario disponer previamente de punto de conexión en las condiciones técnicas definidas reglamentariamente. Ello tuvo consecuencias muy relevantes para la autoridad reguladora nacional (por aquel entonces, Comisión Nacional de Energía) en lo referido a la tramitación de los conflictos de acceso a las redes de distribución, pues no podía conocer del asunto si el solicitante no había obtenido previamente la conexión a la red; lo que redujo sustancialmente el número de conflictos planteados.

La modificación a que nos hemos referido corrió a cargo de la Ley 17/2007, de 4 de julio, por la que se modifica la Ley 54/1997, de 27 de noviembre, del Sector Eléctrico, para adaptarla a lo dispuesto en la Directiva 2003/54/CE, del Parlamento Europeo y del Consejo, de 26 de junio de 2003, sobre normas comunes para el mercado interior de la electricidad (BOE núm. 160, de 5 de julio de 2007). 
En materia de conexión, la GNMC también tendrá competencia para conocer los conflictos de conexión a la red de transporte y distribución de electricidad cuando la autorización de estas infraestructuras sea de competencia estatal. Sin embargo, cuando la competencia en materia de autorización de instalaciones sea atribuida a la Comunidad Autónoma (lo que sucede cuando el régimen de aprovechamiento de las instalaciones no excede del ámbito territorial de la autonomía), los conflictos van a ser resueltos por el órgano competente de la Comunidad Autónoma (alguna evidencia de esta atribución de competencias, y en relación a las redes de distribución, la encontramos en el artículo 42.2 LSE de 1997). Así, esta doctrina ha venido aplicándose con el respaldo de una jurisprudencia consolidada ${ }^{39}$, la cual ha sostenido que el acceso tiene que ver con la formación de un mercado eléctrico, mientras que la conexión está íntimamente relacionada con la seguridad de las instalaciones en cuestión ${ }^{40}$; lo que justifica la atribución de competencias sobre resolución de conflictos de acceso al Estado, ya que la formación de un mercado excede del ámbito autonómico, y la resolución de conflictos de conexión a las Comunidades Autónomas, salvo que exceda del ámbito territorial de la autonomía, al tratarse solo de una conexión física de las instalaciones.

Así, la doctrina del Tribunal Supremo ha establecido que la competencia en materia de acceso es atribuida al Estado como consecuencia del interés propio de la AGE en lo relativo al flujo o tránsito de electricidad a través de las redes, mientras que las competencias autonómicas en materia de conexión responden al interés de estas administraciones en lo relativo a la autorización de las instalaciones cuyos elementos y régimen de aprovechamiento se limiten a su ámbito territorial.

Así pues, el aún no vigente artículo 33 LSE refleja esta doctrina en materia de resolución de conflictos, así como también se refiere a ello el artículo 17 de la

Aunque cabe subrayar que la propuesta de RD de acceso y conexión pretende superar esa inversión secuencial al establecer que la tramitación de los permisos de acceso y conexión se hará de forma conjunta.

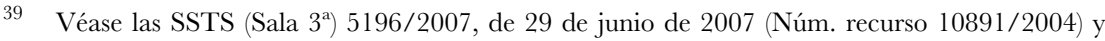
5213/2008, de 8 de octubre de 2008 (Núm. recurso 538/2006).

40 Esta distinción entre acceso y conexión se observa en la Directiva 2009/72/CE, vid. Sentencia del Tribunal de Justicia de las Comunidades Europeas (Sala Tercera), de 9 de octubre de 2008 (asunto G-239/07), la cual dispone que "[...] El término «acceso» se vincula con el abastecimiento de electricidad, incluyendo en particular la calidad, la regularidad y los costes del servicio. Se emplea frecuentemente en el contexto de la garantía de las tarifas no discriminatorias [...]", mientras que "[...] El término «conexión» se utiliza más bien en un contexto técnico y se refiere a la conexión física a la red [...] los Estados miembros velarán por que se definan criterios técnicos de seguridad y se elaboren y publiquen las normas técnicas que establezcan los requisitos técnicos mínimos de diseño y funcionamiento en materia de conexión a la red [...]". Asimismo, destacamos el comentario a esta sentencia de la autora TORRES LÓPEZ, M. A., "El derecho de acceso de terceros a las redes de transporte y distribución de electricidad (Comentario a la STJCE, Sala 3a, de 9 de octubre de 2008, As. C-239/07)", en Noticias de la Unión Europea, núm. 312, 2011, pp. 95-100. 
propuesta RD de acceso y conexión. El apartado segundo de los preceptos citados, sigue reflejando la atribución de competencias en materia de resolución de conflictos de acceso a la CNMC, en sintonía con lo establecido en la legislación vigente (LSE de 1997, RD 1955/2000 y Ley 3/2013). Mientras que los artículos 33.5 LSE y 17.3 de la propuesta RD de acceso y conexión incorporan a la norma la doctrina que la autoridad reguladora nacional (CNMC y, con anterioridad a su creación, CNE) y el Tribunal Supremo viene aplicando hasta la fecha; esto es, atribuir la competencia en materia de resolución de conflictos de conexión a la GNMC cuando se trate de instalaciones de red que competen a la AGE, y para el caso de que competa a la autonomía, atribuir esa competencia a la Comunidad Autónoma en cuestión ${ }^{41}$. Vemos que la LSE es coherente con el modelo de distribución de competencias entre el Estado y las Comunidades Autónomas, de manera que utiliza el criterio de la competencia para la autorización de la instalación de transporte o distribución, a la que va a realizarse la conexión, para otorgar la facultad de resolver los conflictos que puedan suscitarse en relación con la concesión de conexión a estas instalaciones.

Si bien hay que destacar una novedad introducida por estos preceptos que persigue garantizar la aplicación homogénea de criterios: la necesaria aportación de informe previo por parte de la CNMC para los casos en que la Comunidad Autónoma resuelve conflictos de conexión. Presentando este informe carácter vinculante en lo relativo a condiciones económicas y temporales relativas a los calendarios de ejecución de las instalaciones de los titulares de redes recogidas en la planificación de la red de transporte y en los planes de inversión de las empresas distribuidoras aprobados por la AGE. Así, será vinculante en supuestos en que se plantea una controversia tras la denegación de la solicitud de conexión a la red de competencia autonómica, cuando el motivo de denegación sea la no previsión de la instalación (sobre la que se solicita conexión) en la planificación vinculante de la red de transporte o en los planes de inversión de empresas distribuidoras (de competencia estatal en ambos casos).

El Tribunal Constitucional se ha pronunciado recientemente sobre la constitucionalidad del informe previo por medio de la Sentencia 32/2016, de 18 de febrero ${ }^{42}$, en atención de un recurso interpuesto por el Gobierno de la Generalitat de Cataluña. La Comunidad Autónoma alegaba que el informe previo vinculante desplazaba una competencia ejecutiva de la autonomía catalana. Si bien la sentencia concluyó que este mecanismo de los informes vinculantes es admitido como una técnica de acomodación o integración de dos competencias concurrentes, estatal y autonómica, que deben armonizar, disponiendo que "[...] el carácter vinculante del informe no

41 Acerca de las instalaciones de red cuya autorización compete a la Administración estatal o autonómica, véase LEIVA LÓPEZ, A. D. (2018b: 194-195).

42 BOE núm. 71, de 23 de marzo de 2016. 
es sino la consecuencia de ese mismo carácter vinculante atribuido a la planificación eléctrica de la red de transporte [...] por su parte, el informe vinculante sobre los planes de inversión de las empresas distribuidoras aprobados por la Administración General del Estado responde a competencias estatales [...] en relación con el régimen económico del sector [...] la aprobación del plan determina el reconocimiento del derecho a retribución con cargo al régimen económico del sector, segmento específico y diferenciado dentro de la propia materia régimen energético, cuyo establecimiento, dada su trascendencia, corresponde al Estado".

Por último, debemos subrayar que la Directiva 2009/72/CE del Parlamento Europeo y del Consejo, de 13 de julio, sobre normas comunes para el mercado interior de la electricidad ${ }^{43}$ otorga una competencia a la CNMC, en materia de acceso y conexión, que aún no ha sido transpuesta al derecho español. Nos referimos a la competencia para aprobar, con suficiente antelación a su puesta en práctica, las metodologías o tarifas para establecer las condiciones para la conexión y el acceso a las redes de transporte y distribución de electricidad, de manera que quede garantizada la viabilidad de éstas (artículo 37.6.a).

\section{Novedades para productores} renovación

A. La caducidad de los derechos de acceso y conexión y su eventual

La disposición transitoria octava de la LSE de 2013 se refiere a la caducidad de los derechos de acceso y conexión concedidos a generadores. Existen dos circunstancias que dan lugar a esta caducidad: a) No haber obtenido la autorización de explotación de la instalación de generación asociada en el mayor de los siguientes plazos: 1. ${ }^{\circ}$ Cinco años desde la entrada en vigor de la presente ley y $2 .^{\circ}$ Cinco años desde la obtención del derecho de acceso y conexión en un punto de la red; b) Habiendo obtenido la autorización de explotación, y por tanto siendo instalaciones construidas y en servicio, no verter energía a la red durante un período superior a tres años y por motivos imputables al titular de la instalación distintas al cierre temporal. Aparece así la caducidad como elemento novedoso, pues en la regulación anterior a la LSE no se contemplaba (solo se hablaba de caducidad de los procedimientos de autorización), de manera que los derechos de acceso y conexión eran otorgados y mantenidos de forma indefinida, lo que dificultaba la entrada de nuevos agentes a la red.

Específicamente, es la circunstancia a) la que, a la luz de la crisis económica vivida durante muchos años, y que consecuentemente ha ocasionado una ralentización severa de las inversiones en generación y su puesta en servicio, hace necesaria la

43 DOUE núm. 211, de 14 de agosto de 2009. 
regulación de un sistema de renovación de derechos de acceso y conexión. El motivo no es otro que el inminente vencimiento para determinados promotores -finales de diciembre de 2018- del plazo de cinco años a que se refiere la LSE, lo que ocasionaría la caducidad de los derechos de acceso y conexión obtenidos por un elevado número de instalaciones de generación con anterioridad a la entrada en vigor de la LSE y, por tanto, la repetición del procedimiento establecido para su obtención y la pérdida de garantías económicas satisfechas.

Además de esta coyuntura económica de crisis, otro factor determinante a tener en cuenta lo constituye la existencia de diferentes períodos de maduración de las tecnologías de generación de electricidad, los cuales pueden dificultar la puesta en servicio de algunas tecnologías (especialmente para las nuevas tecnologías: fotovoltaica, termosolar, eólica...).

Si bien estos motivos justificarían la necesidad de articular mecanismos para la renovación de derechos de acceso y conexión, ello no debiera cristalizar en la concesión de renovaciones por tiempo excesivo, ya que podría ocasionar intencionados bloqueos de capacidad de manera indefinida. La evitación de esto último debe constituir un objetivo prioritario para poder alcanzar garantías efectivas de libre acceso de terceros a las redes en condiciones de igualdad y, en definitiva, para contribuir positivamente a la formación de un mercado eléctrico basado en la libre competencia.

Destacadamente, se produce un cambio normativo con posterioridad a la elaboración del borrador de reglamento que analizamos por medio del Real Decreto-ley 15/2018, de 5 de octubre, de medidas urgentes para la transición energética y la protección de los consumidores ${ }^{44}$. Este cambio implica retrasar más el plazo de caducidad previsto en el apartado a).1. ${ }^{\circ}$ de la disposición transitoria octava de la LSE, que iba a tener lugar en el mes de diciembre de 2018. Así, el artículo 19.2 Real Decreto-ley 15/2018 da una nueva redacción a la disposición transitoria octava, estableciendo que va a tener lugar la caducidad de derechos a) si no se hubiera obtenido la autorización de explotación en el mayor de los siguientes plazos: 1. ${ }^{\circ}$ antes del 31 de marzo de 2020; $2 .^{\circ}$ Cinco años desde la obtención del derecho de acceso y conexión en un punto de la red.

En este contexto, la propuesta de RD de acceso y conexión prevé la posibilidad de solicitar una renovación consistente en una única prórroga, por período adicional de cinco años, del derecho de acceso y conexión, cuando éste hubiera caducado por no existir autorización de explotación en el plazo establecido. Así, el escenario es el siguiente: para las instalaciones de producción que obtuvieron estos derechos con anterioridad a la entrada en vigor de la LSE (2013), la caducidad llegaría a finales

44 BOE núm. 242, de 6 de octubre de 2018. 
de diciembre de 2018 (disposición transitoria octava LSE), aunque tras la reforma de 2018 se retrasaría a 31 de marzo de 2020; mientras que para quienes obtuvieron estos derechos con posterioridad a la entrada en vigor de la LSE y antes de la entrada en vigor de la propuesta de RD de acceso y conexión (disposición transitoria primera de la propuesta) y para los que obtengan permisos tras la entrada en vigor de la propuesta de RD de acceso y conexión (artículo 23.1 de la propuesta), caducarán a los cinco años desde obtenidos los derechos o permisos de acceso y conexión. En todos los casos la caducidad tiene lugar si no se ha obtenido, llegado el plazo máximo, la autorización de explotación de la instalación. En este punto, entendemos que más allá de exigir la obtención última de la autorización de explotación, se demandan hitos administrativos intermedios, con plazos de caducidad definidos al efecto, que atiendan el tipo de tecnología (con distintos grados de madurez), los distintos estados de desarrollo de las instalaciones (debe diferenciarse entre promotores que aún no han empezado la construcción de aquellos que ya han acometido inversiones) y que valoren la posible imputación de dilaciones en la obtención de autorizaciones anteriores a la de explotación (autorización previa y autorización de construcción) a agentes distintos al promotor.

Así, la propuesta de RD de acceso y conexión regula un procedimiento de renovación de derechos y permisos de acceso y conexión. El artículo 24 se refiere a la renovación de aquellos obtenidos a partir de la entrada en vigor del texto. Mientras que la disposición transitoria segunda de la propuesta define el procedimiento a seguir para productores que hubieran obtenido los derechos de acceso y conexión con anterioridad a la entrada en vigor de la LSE. No queda tan claro, sin embargo, el procedimiento de renovación para productores cuyos derechos de acceso y conexión hubieran sido obtenidos tras la entrada en vigor de la LSE y antes de la entrada en vigor de la propuesta de RD de acceso y conexión.

De un lado, el mencionado artículo 24 admite la posibilidad de renovación "una única vez", por lo que debemos entender una prórroga adicional de cinco años, lo que implica que las solicitudes podrán estar en tramitación un plazo máximo improrrogable de 10 años. La solicitud tendrá que cursarla el propio titular de los derechos, o en su caso el interlocutor único de posición cuando se trate de tecnología renovable (sucesor, como vemos en adelante, del Interlocutor Único de Nudo), con una antelación de un mes desde la fecha de su caducidad (caso de no hacerlo, se perderá el derecho de renovación y solo cabría obtener acceso y conexión por medio de una solicitud nueva), y será dirigida al titular de la red en cuestión. Esta solicitud deberá acompañar: i) declaración responsable acerca del mantenimiento de la totalidad de condiciones bajo las cuales se concedieron los permisos de acceso y conexión; ii) garantía económica adicional por valor de 3 veces la establecida en el RD 1955/2000 (10€/kW instalados); lo que ascendía, a la fecha de elaboración 
del borrador de reglamento, a una cuantía equivalente a $30 € / \mathrm{kW}$ instalados ${ }^{45}$. Sin embargo, de mantenerse la propuesta de reglamento, esta cuantía sería mayor si observamos la reciente modificación del RD 1955/2000 operada a través del Real Decreto-ley 15/2018. Este cambio supone la modificación del importe de garantía económica que debe abonarse, pasando de $10 € / \mathrm{kW}$ instalados a $40 € / \mathrm{kW}$ instalados. Por lo que, de aprobarse el RD de acceso y conexión en estos términos, la cuantía a abonar para la renovación de derechos sería el resultado de multiplicar por 3 esta nueva garantía económica.

Esta garantía económica de mayor cuantía dará más firmeza a la tramitación y persigue garantizar cierto equilibrio entre los intereses de un solicitante que inició el procedimiento cinco años atrás, y quiere poner en marcha el proyecto, y de los nuevos eventuales agentes entrantes que también puedan tener interés en conectarse a un mismo punto que podría verse bloqueado por instalaciones que están en tramitación. Aunque cabría plantearse si estas cuantías son aún insuficientes para la evitación de posibles bloqueos de puntos de conexión por períodos de hasta 10 años, los cuales seguirían permitiendo adoptar estrategias especuladoras a sus promotores ${ }^{46}$.

De no cumplirse con estos requisitos, la solicitud podrá ser inadmitida. Asimismo, el titular de la red podrá requerir subsanación al solicitante en el plazo de 15 días. En su caso, la tramitación de la solicitud, una vez admitida, tendrá prioridad sobre nuevas solicitudes. El titular de la red dispondrá de 15 días para comunicar la

45 En este punto, los artículos 59bis (transporte) y 66bis (distribución) RD 1955/2000 obligan a presentar resguardo acreditativo de haber depositado una garantía económica, en modalidad de efectivo o aval prestado por entidades de crédito o sociedades de garantía recíproca, por una cuantía equivalente a $10 € / \mathrm{kW}$ instalados. Existiendo exenciones a la presentación de tal garantía para determinadas instalaciones que quieran acceder a la red de distribución.

46 Es el denominado mercadeo de los puntos de conexión del que se benefician ciertos agentes del sector. Así, estos agentes obtienen derechos de acceso y conexión en un punto de la red, con el único coste económico que suponen los avales (10.000 €/MW instalado), pero sin ninguna intención de desarrollar proyecto alguno. De esta forma, cuando otros agentes quieren conectarse al mismo punto de red sobre el que han obtenido los derechos de acceso y conexión, comienza un proceso de negociaciones; esto es, de venta de la empresa. Es entonces cuando el agente, con un ánimo puramente especulativo, ofrece ese punto a cantidades muy por encima de las que abonaron en concepto de aval (llegando a cuantías de hasta 100.000 $€ / M W$ instalado); lo que termina cristalizando en la venta efectiva, habida cuenta de que buscar otro punto o llevarte la línea a otro lado puede suponer un coste mayor para el nuevo agente peticionario. Estos agentes se benefician de momentos en que los puntos de conexión son muy demandados, como por ejemplo tras las grandes subastas de energías renovables, como sucede actualmente con las acontecidas recientemente en los años 2016 y 2017. Véase https://elperiodicodelaenergia.com/asi-es-el-vergonzoso-mercadeo-permitidode-los-puntos-de-conexion-a-la-red-electrica-en-espana/.

Con la nueva normativa, estos especuladores tendrán que abonar cantidades más elevadas en concepto de aval si quiere ver renovados sus permisos, lo que en principio supone un paso adelante en la lucha contra los bloqueos de capacidad especulativos, aunque cabe plantearse si ello será suficiente. 
concesión o denegación, cuando no se trate de la misma instalación ${ }^{47}$, de la renovación de permisos.

Por último, cabe señalar que las discrepancias que pudieran suscitarse en relación a la denegación de las solicitudes de renovación van a ser resueltas por el órgano competente de conformidad con las reglas definidas en materia de resolución de conflictos de acceso y conexión (remisión al epígrafe 2.B).

De otro lado, la disposición transitoria segunda de la propuesta de RD de acceso y conexión va a regular el procedimiento para la obtención de renovación que deben seguir aquellos productores, cuyos derechos de acceso y conexión hubieran sido obtenidos con anterioridad a la entrada en vigor de la LSE de 2013, y que caducaban, a la fecha de elaboración de la propuesta de real decreto, a finales de diciembre de 2018. Si bien, tras la reforma de 2018, pasarían a caducar en fecha 31 de marzo de 2020.

Los interesados van a tener un plazo de 3 meses desde la entrada en vigor del real decreto para formalizar sus solicitudes, las cuales vendrán acompañadas de la aceptación de las condiciones técnicas y económicas y de las garantías a que se refiere el artículo $16^{48}$. Caso de no aportarse estas garantías una vez renovados los permisos, el titular dispondrá de un período de tres meses para constituirlas y presentarlas al titular de la red en cuestión. Y de no hacerlo en este plazo, se produciría la caducidad de los permisos de acceso y conexión. Asimismo, se va seguir el procedimiento de renovación previsto en el artículo 24, el cual incluye la aportación de garantía económica adicional por valor de 3 veces la establecida en el RD 1955/2000 (que, como hemos indicado, pasaría a ser ahora de $40 € / \mathrm{kW}$ instalados).

Sobre la aceptación de las condiciones técnicas y económicas que acompañan a la solicitud, caso de no acreditarse tal aceptación, los solicitantes deberán tramitar la renovación de permisos aportando toda la información requerida a que se refiere el Capítulo III, y teniendo en cuenta las siguientes particularidades: i) Que el titular de

$47 \quad$ El anexo VIII de la propuesta de RD de acceso y conexión se refiere a las características de la instalación que caso de ser modificadas supondría encontrarnos ante una instalación que "no es la misma" a los efectos de la renovación: $i$ ) Tecnología de generación; ii) Potencia instalada, cuando la variación suponga un aumento del $5 \%$; iii) Ubicación, cuando menos del $50 \%$ de la superficie de su envolvente se encuentre dentro de la misma parcela.

48 El cual dispone que los solicitantes, para los puntos de conexión superiores a $1 \mathrm{kV}$ en los que la totalidad o parte de las actuaciones llevadas a cabo en las redes deban ser sufragadas por ellos mismos como titulares de los permisos, y éstas deban ser desarrolladas por el propietario de la red en cuestión, deberán presentar al titular de la red una garantía económica de al menos el 25 \% del valor de la inversión (el cual incluye la posición de conexión y los trabajos de refuerzos, adecuación, adaptación o reforma de las instalaciones de red necesarias para la conexión). Se trata de una garantía que se podrá hacer efectiva mediante pago al contado o por medio de instrumentos financieros equivalentes. 
la red tramitará la solicitud con preferencia respecto a otras solicitudes cursadas para el mismo nudo o posición; ii) Que de considerarse la instalación como "la misma" a los efectos de renovación, de conformidad con los criterios ya observados del Anexo VIII, no podrán denegarse los permisos por inexistencia de capacidad de acceso y conexión.

Las garantías a que se refieren los preceptos 16 y 24 entendemos que también debieran ser satisfechas por aquellos productores que quieran renovar los derechos de acceso y conexión obtenidos tras la entrada en vigor de la LSE y antes de la entrada en vigor de la propuesta de RD de acceso y conexión. Por lo que cabe esperar que el texto definitivo haga referencia a este punto.

Por último, cabe significar que el establecimiento de este modelo de renovación de permisos implica cierto debate en cuanto a la técnica jurídica empleada para su regulación, ya que la duración de estos derechos y avales regulados en la LSE se estaría modificando a través de una norma con rango inferior a ley. Cabría plantearse qué puede suceder si un eventual agente con interés en acceder a un mismo punto del nudo de conexión cuestionara la validez legal de renovaciones de derechos que pudieran estar ocasionando un bloqueo del punto al que se quiere acceder. En cualquier caso, si los tribunales se pronunciaran acerca de la posible nulidad de las renovaciones otorgadas, no entendemos viable la expulsión del sistema de quienes ya hubieran entrado al sistema, lo cual no es óbice a que se buscasen soluciones alternativas compensatorias para aquellos solicitantes que hubieran quedado fuera por este motivo.

Por otro lado, se han echado en falta hasta la fecha incentivos que llevasen a generadores solicitantes a retirar sus proyectos cuando sea prevea que no van a salir adelante. La regulación preveía la pérdida del aval completo cuando los derechos de acceso y conexión caducan, lo cual no ha generado para el promotor ningún incentivo para retirarse, ya que perdería la totalidad del aval independientemente del momento en que retire su proyecto. Esto ha provocado el bloqueo de capacidades en un punto de la red durante el plazo de vigencia de los derechos de acceso y conexión obtenidos (5 años); lo que entendemos podría solucionarse creando hitos administrativos intermedios encaminados a incentivar la retirada de proyectos a través de penalizaciones que no supongan la cancelación íntegra del aval, sino que se fije por porcentajes atendiendo al momento en que se retira el proyecto. Quizá también cabría plantearse incrementar la cuantía del aval.

En este punto, el Real Decreto-ley 15/2018, en su disposición adicional tercera, prevé que aquellas instalaciones que dispongan de los permisos de conexión y acceso que no vayan a cumplir los plazos definidos, van a poder renunciar a su derecho de conexión y acceso, y, en consecuencia, se les devolverían las garantías aportadas; esto es, recuperarían los costes satisfechos, a excepción de aquellos no recuperables en que 
hubiese incurrido el titular de la red hasta el momento. Si bien, aunque esta medida incentivaría la retirada de proyectos, se siguen echando en falta los hitos intermedios, que atiendan cada situación particular, a que nos hemos referido.

Asimismo, resulta preocupante la falta de sintonía entre la forma de cómputo de plazos previsto en la normativa estatal a la hora de calcular la caducidad de derechos de acceso y conexión y de los plazos definidos en la normativa autonómica para el cálculo de la caducidad de los procedimientos de autorización administrativa. $\mathrm{S}$ e manejan conceptos de caducidad con plazos distintos y formas de cómputo distintos que debieran corregirse.

\section{B. Presentación de garantía económica}

Para la generación, de conformidad con lo dispuesto en los artículos 59bis (transporte) y 66bis (distribución) RD 1955/2000, como requisito previo a la presentación de la solicitud de acceso a las redes de transporte y distribución, los solicitantes deben presentar ante el órgano competente para otorgar la autorización de la instalación, o ante la Caja General de Depósitos si son instalaciones de competencia de la AGE, resguardo de haber depositado una garantía económica que, tras la modificación mencionada de 2018, equivaldría a $40 € / \mathrm{kW}$ instalados. La confirmación por el órgano competente de la adecuada constitución de los avales deberá acompañar a la solicitud de acceso que el solicitante dirige al gestor de la red de transporte o distribución.

Específicamente, para el acceso a la red de distribución, estarán exentas de la presentación de estas garantías las instalaciones de potencia igual o inferior a 10 $\mathrm{kW}$ o aquellas instalaciones de generación destinadas al autoconsumo que no sean consideradas instalaciones de producción. Estas últimas son las definidas, en el RD 900/2015, de 9 de octubre, por el que se regulan las condiciones administrativas, técnicas y económicas de las modalidades de suministro de energía con autoconsumo y de producción con autoconsumo ${ }^{49}$, como instalaciones de autoconsumo instantáneo o "tipo 1" y que no vierten a la red su energía excedentaria.

Esta garantía, en modalidad de efectivo o aval prestado por entidades de crédito o sociedades de garantía recíproca, ha sido considerada insuficiente por distintos sectores, ya que atrae comportamientos especulativos en el sentido a que nos hemos referido en el apartado anterior.

Sobre la ejecución de la garantía, cabe significar que según lo dispuesto en el RD 1955/2000 ésta tendrá lugar cuando: i) exista desistimiento por parte del solicitante en la construcción de la instalación; ii) caducidad de los procedimientos de

49 BOE núm. 243, de 10 de octubre de 2015. 
autorización administrativa de la instalación; iii) incumplimiento de los plazos definidos para las autorizaciones preceptivas.

La circunstancia ii) del reglamento ha implicado durante mucho tiempo la ejecución de los avales y la consecuente obligación de iniciar de nuevo la tramitación de autorizaciones administrativas, pero en ningún caso ello implicaba la pérdida por parte del solicitante de los derechos de acceso y conexión obtenidos en el procedimiento previo al trámite de autorizaciones. Esta regulación ha provocado bloqueos de capacidad en ciertos puntos de la red, los motivos son: a) ciertos comportamientos especulativos por parte de agentes solicitantes que, asumiendo la pérdida del aval, han mantenido los derechos de acceso y conexión hasta encontrar una situación de mercado óptima para su venta; b) la falta de instrumentos que incentivasen a generadores a retirar sus proyectos cuando las previsiones de salir adelante eran adversas, de manera que estos, habida cuenta de que perderían la cantidad de aval íntegra independientemente del momento de retirada, no veían inconveniente en mantener sus instalaciones hasta llegada la ejecución del aval por caducidad de procedimientos de autorización.

Pero tras la aprobación de la LSE en 2013, su disposición transitoria octava ha venido estableciendo que los derechos de acceso y conexión también van a caducar cuando el solicitante generador no hubiera obtenido autorización de explotación en cinco años desde la entrada en vigor (modificado por el Real Decreto-ley 15/2018) o desde la obtención del derecho de acceso y conexión. Esto pone fin a las posibles conductas especulativas a que nos hemos referido, ya que además de la ejecución del aval, se perderán los derechos de acceso y conexión. Sin embargo, se han seguido echando en falta mecanismos que inviten a solicitantes a desistir, pues el aval se seguiría perdiendo en su totalidad al margen del momento de retirada de proyectos. Aunque el Real Decreto-ley 15/2018, y específicamente su disposición adicional tercera, ha supuesto una mejora sustancial, al permitir a los promotores recuperar los costes, a excepción de aquellos no recuperables en que hubiese incurrido el titular de la red. Sin embargo, entendemos que seguiría siendo aconsejable en este punto que hubiese ejecuciones parciales del aval que atiendan al momento de retirada de un proyecto fallido.

Por su parte, la propuesta de RD de acceso y conexión sigue exigiendo, en su artículo 7, la aportación de garantías económicas según lo establecido en los artículos 59bis y 66bis RD 1955/2000. Si bien, de conformidad con el artículo 16 de la propuesta, en un espacio temporal posterior, una vez obtenido el permiso de acceso y conexión, obliga a los titulares de permisos a aportar otra garantía adicional distinta al aval de acceso. El precepto dispone, como novedad, que esta confirmación económica del pago de aval debe llegar tras la obtención provisional de los permisos 
de acceso y conexión y que, además, atenderán a unos plazos definidos en función del nivel de tensión debido al tiempo de maduración de los proyectos. Así pues, en los puntos de tensión superior a $1 \mathrm{kV}$, donde la totalidad o parte de las actuaciones que deben realizarse en las redes deben ser pagadas por los solicitantes de acceso y conexión y desarrolladas por los titulares de las redes, los solicitantes de acceso y conexión deberán presentar al propietario de la red una garantía económica de al menos un $25 \%$ del valor de inversión (que incluye la posición de conexión y los trabajos de refuerzo, adecuación, adaptación o reforma de instalaciones de la red requeridas para la conexión), en un plazo no superior a: i) 6 meses para instalaciones de tensión inferior a $36 \mathrm{kV}$; ii) 12 meses para instalaciones de tensión superior o igual a $36 \mathrm{kV}$ e inferior a $220 \mathrm{kV}$; iii) 18 meses para instalaciones de tensión superior o igual a 220 $\mathrm{kV}$ e inferior a $380 \mathrm{kV}$; iv) 24 meses para instalaciones de tensión igual o superior a $380 \mathrm{kV}$. Todos los plazos computan a partir de obtenidos los permisos de conexión y acceso provisionales y caso de no cumplirse darán lugar a la caducidad de estos.

\section{El Interlocutor Único de Posición (IUP)}

La nueva regulación contempla la sustitución de la figura del Interlocutor Único de Nudo (IUN) por el Interlocutor Único de Posición (IUP). Vemos en adelante qué cambios se han introducido en este punto.

El Interlocutor Único de Nudo (IUN) aparece regulado en el apartado cuarto del Anexo XV RD 413/2014. Así, la tramitación del procedimiento de acceso a la red de transporte de instalaciones de producción mediante fuentes renovables, cogeneración y residuos, «cuando varios generadores compartan punto de conexión a la red de transporte [...]», se llevará a cabo, ante el Operador del Sistema y Gestor de la Red de Transporte (REE), de forma conjunta con el procedimiento de conexión. Asimismo, este procedimiento tendrá lugar de forma coordinada por un Interlocutor Único de Nudo (IUN), quien «[...] actuará en representación de los generadores, en los términos y con las funciones que se establezcan» que se encuentren en cualquier posición del nudo.

La potencia de instalaciones que pretenden conectarse a la red de transporte es generalmente inferior a las capacidades existentes en el nudo concreto, por lo que varias instalaciones se pueden ver obligadas a compartir infraestructuras de evacuación y, por tanto, a acudir a la función de representación y coordinación que ostenta este interlocutor.

Además, el papel del IUN también estará presente tras la puesta en servicio de la generación para una mejor coordinación entre los generadores mediante fuentes de energías renovables, cogeneración y residuos, que comparten punto de conexión a la red de transporte, y el Operador del Sistema. 
Esta figura será designada por las Administraciones competentes y será responsable de garantizar que se cumplen los requisitos técnicos relativos a conexión de instalaciones de generación y a la operación coordinada de las instalaciones de conexión a la red de transporte. De no efectuarse una solicitud de forma coordinada con el IUN, el Operador del Sistema atenderá la misma subrayando la necesidad de que se respete el cauce procedimental definido a tal efecto. En este punto, cabe añadir que las coordenadas de contacto de los IUN se encuentran accesibles en la página web corporativa de REE.

En este punto, la propuesta de RD de acceso y conexión crea una nueva figura, que viene a sustituir al IUN, con la finalidad de optimizar la utilización de las redes de transporte y, también ahora, distribución, así como de minimizar el impacto ambiental. Se trata del Interlocutor Único de Posición (IUP), figura regulada en el artículo 8 de la propuesta que será designada atendiendo a un orden de antigüedad en la obtención de derechos o presentación de solicitudes o, en su defecto, al acuerdo celebrado entre las partes; desapareciendo así la intervención de la Administración en este nombramiento.

Como dispone el precepto, éste se encargará de representar en el procedimiento de acceso y conexión a varios titulares o promotores de instalaciones de generación cuando se conectan a una misma posición de tensión superior a $36 \mathrm{kV}$ de una subestación, con la finalidad última de que estos compartan infraestructuras de evacuación para conectarse a esa posición única. Por lo que, como novedad, la figura se extiende a los posibles puntos de conexión en posiciones de la red de distribución por encima de esa tensión, así como restringe su ámbito de actuación a la posición concreta del nudo al que se conecta, a diferencia de la figura anterior que representaba la totalidad de un nudo. Ello evita comportamientos no deseados por parte del interlocutor que pudieran bloquear la tramitación de solicitudes de acceso y conexión.

Además, permitirá que caso de no existir capacidad en una posición concreta o de existir restricciones de otro tipo impuestas por el interlocutor, se pueda acudir a otra posición cuyas solicitudes pudieran estar representadas por otro interlocutor. Destacadamente, se consideran habilitadas con carácter general dos posiciones de reserva adicionales, además de las incluidas en la planificación, de forma que el solicitante, sin necesidad de pasar por el procedimiento de aprobación de nuevas posiciones en la planificación, encuentre mayor facilidad a la hora de efectuar su conexión en una subestación ante posibles restricciones en la posición sobre la que solicitó conectarse. Sin embargo, esto podría no ser del todo satisfactorio en ciertos nudos de la red de transporte donde la ampliación física deviene inviable por existir una capacidad de cortocircuito saturada. Por tanto, habrá que atender las particularidades de cada zona geográfica. 
Por otro lado, habrá que distinguir dos supuestos: i) Si no existiera un IUN en el punto concreto a la entrada en vigor de la propuesta (artículo 8), el solicitante de permiso de acceso y conexión será designado como tal por el titular de la red sobre la que se solicitan los permisos. Aunque cabe la posibilidad de que los interesados en una posición concretan acuerden designar a otro sujeto, lo que tendrán que comunicar al titular de la red. El sujeto designado tendrá que cursar y gestionar las solicitudes de todos los interesados en una misma posición respetando la prelación temporal de éstas, para así evitar los posibles bloqueos a que nos hemos referido, lo cual no había sido reflejado hasta ahora con tanta claridad. Recibida la solicitud de acceso y conexión, el titular de la red debe informar acerca de la existencia o inexistencia de interlocutores en cada posición, lo cual puede ocasionar que solicitantes decidan dirigirse a otro interlocutor o cursar una nueva solicitud en una posición donde no hay designado ninguno. Y es que el interlocutor es un agente más que dispone de información y ésta debe ser accesible por todos. Si el interlocutor no traslada las solicitudes al titular de la red, fuera de los casos en que está legitimado para ello (falta de documentación, de compromisos de pago o de capacidad suficiente en la posición solicitada), o existen otras discrepancias relativas a las relaciones con éste, los peticionarios podrán plantear conflicto de acceso y conexión en los términos ya examinados; y ii) Caso de existir ya IUN a la entrada en vigor de la propuesta (disposición transitoria tercera), tendrá lugar la conversión de éste en IUP. El criterio será designar como IUP al primer generador que hubiera obtenido los derechos de acceso y conexión o, en caso de no existir, el primero que lo hubiera solicitado. Aunque cabe la posibilidad de que por acuerdo de los generadores ya conectados o representados por interlocutor designen otro sujeto como IUP, lo que deberán comunicar al titular de la red.

En definitiva, el IUP aparece como una figura instrumental que trata de lograr un mayor equilibrio entre el bien colectivo, que es la capacidad de acceso y conexión disponible en la red de transporte y distribución de elevada potencia, y los intereses particulares de los promotores. Vemos que para su designación es necesario un acuerdo entre las partes implicadas, que minimizan posibles conflictos de intereses, porque las capacidades de red constituyen un bien público que no puede restringirse por un interés particular de quien hubiera obtenido primero los derechos de acceso y conexión o, en su caso, hubiera presentando la solicitud. Aunque en este punto quizá la norma debiera incentivar también una figura del todo independiente, ajena incluso al sector, que no tuviera intereses económicos particulares en el nudo. Lo que, unido a una mayor automatización de los trámites coherente con el avance tecnológico, podría cristalizar en un modelo de acceso y conexión a las redes donde los bloqueos de capacidad brillen por su ausencia. 
También cabría plantearse si al menos en distribución podría prescindirse de esta figura, pues en ocasiones se ha cuestionado que el valor que aporta la función intermediadora del interlocutor pudiera ser inferior al propio que aportaría el gestor de la red de distribución.

Si bien es positivo el paso de una figura a otra al permitir a los promotores elegir distintas posiciones dentro de una misma subestación, teniendo por tanto alternativas a una eventual denegación por parte del interlocutor, se echa en falta, por otro lado, una relación detallada de funciones y plazos, así como de un régimen de responsabilidades económicas para supuestos de incumplimiento por parte del interlocutor. Cuestión ésta de interés, pues el interlocutor actúa en cierto modo como juez y parte, representando una función intermediadora y de gestión que debiera tener mayor cobertura regulatoria.

\section{Novedades para autoconsumidores}

A. Cuestiones introductorias

Las tecnologías basadas en fuentes de energía renovables empleadas para el autoconsumo de electricidad experimentan cada vez mayores avances y madurez tecnológica (especialmente, las instalaciones fotovoltaicas), lo que, unido a los progresos obtenidos en materia de almacenamiento energético a pequeña escala (destacando las baterías para uso doméstico $)^{50}$, lanza importantes retos en materia de configuración de requisitos técnicos para el acceso y conexión de estas instalaciones a las redes.

Todo ello en un escenario político internacional y europeo -destacadamente la COP $21^{51}$ y el «Winter Package ${ }^{52}$ - que otorga un papel protagonista al las energías

50 Destaca la batería Powerwall de Tesla, que fue lanzada al mercado en el año 2015, la cual utiliza una tecnología ion-litio con potencial suficiente para permitir al usuario almacenar la energía que genera y autoabastecerse o, incluso, vender la energía al sistema en aquellas horas en que tiene excedente. A pesar de encontrarse aún en una fase temprana de desarrollo, ya existe una segunda generación de esta batería, de 2017, con una capacidad de almacenar energía sobrante de hasta $13,5 \mathrm{kWh}$, lo que permitiría abastecer a una vivienda tipo de cuatro habitaciones durante un día completo. Véase KAZIMIERSKI, M. A., "Almacenamiento energético frente al inminente paradigma renovable: el rol de las baterías ion-litio y las perspectivas sudamericanas", en Letras Verdes, núm. 23 (2018), pp.120-121.

$5121 .^{\text {a }}$ Conferencia de las Partes de la Convención Marco de las Naciones Unidas sobre el Cambio Climático de 2015 (COP21/CMP11), también conocida como «París 2015» o «Cumbre del Clima de París», celebrada en la capital francesa entre el 30 de noviembre y el 11 de diciembre de 2015. Donde los Estados integrantes, bajo la supervisión de EE.UU. y China, manifestaron un interés común y firme por hacer frente al cambio climático.

52 Como novedad que va a afectar a la propuesta de Directiva del Parlamento Europeo y del Consejo relativa al fomento del uso de energía procedente de fuentes renovables -COM (2016) 767 finalcontenida en el Paquete de Invierno Energético, cabe destacar el reciente acuerdo adoptado por representantes del Parlamento Europeo, el Consejo y la Comisión Europea, de 14 de junio de 2018, a través del cual 
renovables y, en particular, al autoconsumo de electricidad basado en fuentes de energía renovables, lo que convierte al autoconsumidor (también denominado prosumidor) en pieza clave para la consecución de un modelo energético donde la aportación de los combustibles fósiles vaya disminuyendo gradualmente ${ }^{53}$. Así, los titulares de las redes deben asumir el importante reto de atender y gestionar la multiplicidad o bidireccionalidad en la energía que, como consecuencia de la interacción del autoconsumidor con la red, va a existir en sus infraestructuras. Para lo que resultaría de gran utilidad la introducción de mecanismos de flexibilidad que superen los límites de inversión que a día de hoy tienen los distribuidores y el desarrollo normativo de incentivos a la innovación en las redes eléctricas que favorezca la reducción de costes de inversión.

Hasta la fecha, la regulación básica de las distintas figuras de autoconsumo la encontramos en el artículo 9 LSE, recientemente modificado por el Real Decreto-ley 15/2018. Mientras que los requisitos técnicos que deben cumplir aquellas instalaciones que vayan a ser destinadas al autoconsumo de energía eléctrica en el marco del procedimiento de acceso y conexión a la red aparecen fundamentalmente regulados en el RD 900/2015 ${ }^{54}$. Aunque cabe subrayar que existe la posibilidad de que la instalación de autoconsumo no se conecte a la red, figura conocida como "autoconsumo aislado" ${ }^{55}$, en cuyo caso no le serían de aplicación las disposiciones contenidas en el reglamento y, en consecuencia, no tendría que sufragar los costes y servicios del sistema.

Desde la entrada en vigor del RD 900/2015 han sido muchas las objeciones planteadas en torno a la posible inconstitucionalidad de algunos de sus preceptos (fundamentalmente en materia de autoconsumo compartido y registros administrativos), siendo varias de ellas objeto de pronunciamiento por parte de los tribunales españoles.

se comprometen a que un $32 \%$ de energía consumida provenga de fuentes renovables para el año 2030. Vid. European Commission Statement "Europe leads the global clean energy transition: Commission welcomes ambitious agreement on further renewable energy development in the EU": http://europa.eu/rapid/press-release_STATEMENT-18-4155_en.htm.

53 LEIVA LÓPEZ, A. D., "La regulación del autoconsumo de electricidad en un nuevo entorno social y tecnológico", en Revista Vasca de Administración Pública, núm. 110, tomo 1 (2018a), pp. 118-119.

54 A mayor abundamiento sobre la regulación legal y los avances en materia de autoconsumo, vid. ORTIZ GARCÍA, M. "El autoconsumo de electricidad en España y su (primera) ordenación jurídica. Un avance (lento) hacia el imparable cambio de modelo energético", en I. REVUELTA PÉREZ (dir.), La regulación de las energías renovables a la luz del Derecho de la Unión Europea, Ed. Thomson Reuters Aranzadi, Cizur Menor, 2017, pp. 453-532.

55 La posibilidad real de que el autoconsumidor, habida cuenta del desarrollo tecnológico actual, se desconecte de la red es muy remota, pues los aparatos eléctricos necesitan la frecuencia, tensión y potencia que proporciona la red como respaldo. LEIVA LÓPEZ, A. D. (2018 a 136). 
En este orden de cosas, la propuesta de RD de acceso y conexión, con el fin de evitar la dispersión normativa, ha emprendido la modificación de algunas de estas disposiciones, para dar cumplimiento a los recientes pronunciamiento de la judicatura al respecto y en aras de lograr beneficios para el conjunto del sistema. Asimismo, se crean medidas que simplifican los requisitos técnicos del autoconsumo para así posibilitar un desarrollo de la generación distribuida ordenado y compatible con la adecuada gestión de la operación del sistema. A continuación, analizamos cuáles son estas revisiones contenidas en la propuesta.

B. Exención de la obligación de obtener los permisos de acceso y conexión

La propuesta de RD de acceso y conexión establece un procedimiento general para la obtención de los permisos de acceso y conexión (artículos 9 a 17) y, como novedad, un procedimiento abreviado (artículo 18). Este último, al que solo podrán acogerse sujetos en los que concurran circunstancias específicas (consumidores o generadores con una potencia inferior a $15 \mathrm{~kW}$ ), será similar al general, pero con unos plazos que se verán reducidos a la mitad. Estos procesos de acceso y conexión van a dotar de viabilidad a aquellas instalaciones de generación, fundamentalmente no gestionable, de manera que quede garantizada su operabilidad en el horizonte 2030.

Sin embargo, para las instalaciones de autoconsumo con contratos de acceso vigentes se prevé, en el artículo 19, una exención de la obligación de obtener estos permisos a través de cualquiera de los dos procedimientos establecidos cuando éstas dispongan de mecanismos antivertido o inyección cero; es decir, podrán acogerse a esta exención solo las instalaciones pertenecientes a la modalidad de suministro con autoconsumo -tipo 1- (también denominado autoconsumo instantáneo) definida en los artículos 9.1.a) LSE y 4.1.a) RD 900/2015. Por su parte, el Real Decreto-ley 15/2018 (disposición adicional segunda) se refiere a esta exención para una modalidad que pasaría a denominar como autoconsumo sin excedentes.

Esta modalidad implica que la electricidad generada por el autoconsumidor va directamente a los aparatos eléctricos y, por tanto, se consume de forma instantánea en el mismo momento en que se produce. De manera que el autoconsumidor tendrá la consideración de "sujeto consumidor", pero no productor, pues no vende su energía sobrante.

La aplicación de tal exención requiere del autoconsumidor tipo 1 que disponga del contrato de acceso para el consumo en vigor que se regula en el artículo 8 del RD $900 / 2015$, el cual establece la obligación de que el consumidor suscriba un contrato de acceso para el consumo con la empresa distribuidora directamente o a través de la empresa comercializadora, o modificar el existente, de conformidad con la normativa aplicable. 


\section{Procedimiento abreviado de conexión de instalaciones}

Una vez obtenidos los permisos de acceso y conexión (que para el autoconsumidor con mecanismos antivertido se identifica con el contrato de acceso a que nos hemos referido supra) y construida la instalación, será necesario acudir a un procedimiento para la conexión efectiva de instalaciones a la red. En este punto, la propuesta de RD de acceso y conexión regula también un procedimiento general (artículo 21) y un procedimiento abreviado (artículo 22) de conexión a la red; pudiendo acogerse a este último aquellos autoconsumidores, con el interés de conectar sus instalaciones de generación para autoconsumo a través de su red interior, que dispongan de contrato de acceso en vigor y de mecanismos antivertido. Vemos, por tanto, que el criterio es el mismo que el empleado para conceder exenciones en materia de obtención de permisos, por lo que aquellos autoconsumidores que no pudieran acogerse a tal exención definida en el artículo 19 -modalidad tipo 2- tampoco podrán acudir a un procedimiento abreviado a la hora de llevar a cabo la conexión efectiva de sus instalaciones.

En este procedimiento abreviado definido en el artículo 22, el prosumidor debe formalizar una solicitud a través de un modelo simplificado, lo que podrá hacer de forma simultánea con otra actuación que también es posterior a la obtención de los derechos de acceso y conexión y a la construcción de la instalación, y necesaria para conectar la instalación a la red: la suscripción del contrato técnico de conexión (que vendría a sustituir a la figura del contrato técnico de acceso). Finalizado el procedimiento de conexión, tendrá lugar la puesta en servicio de la instalación de autoconsumo, para lo que el titular de ésta deberá comunicar al titular de la red, con antelación de cinco días, la fecha y hora a la que se va a realizar, por si éste quisiera estar presente.

\section{El autoconsumo colectivo}

El artículo 4.3 RD 900/2015 dispone que «En ningún caso un generador se podrá conectar a la red interior de varios consumidores». Se trata de un precepto de capital importancia, pues impide que autoconsumidores (que pudieran encontrarse en un edificio dividido en propiedad horizontal, casas adosadas u otras modalidades complejas) compartan la línea de conexión de un generador a la red interior. Por tanto, esta prohibición aparece como un obstáculo al autoconsumo colectivo (también denominado compartido o vecinal). Además, cabe significar que se trata de una materia cuya competencia ha sido reclamada por las Comunidades Autónomas, pues entienden que estas instalaciones, de pequeño tamaño y para el consumo en una misma ubicación, no presentan una incidencia significativa desde el punto de vista técnico y de la gestión de la energía, por lo que no se justifica el carácter básico de aplicación (conforme al artículo 149.1.25 CE) que daría cobertura a la competencia estatal asumida. 
Las Directivas 2009/72/CE y 2009/28/CE del Parlamento Europeo y del Consejo, de 23 de abril, relativa al fomento del uso de energía procedente de fuentes renovables ${ }^{56}$ han subrayado la importancia de la generación descentralizada (siendo una de sus más eficaces tecnologías la del autoconsumo colectivo) como pieza clave para caminar hacia un nuevo modelo energético, donde la configuración de trayectos más cortos de transporte de electricidad va a proporcionar mayor seguridad del suministro local de energía ${ }^{57}$. También, desde una perspectiva teórica, la integración de la generación distribuida renovable, al reducir largas distancias de transmisión y mejorar la conectividad, va a contribuir a la reducción de pérdidas energéticas en la transmisión, pues el nivel de éstas depende, entre otras, de la longitud y sección del conductor $^{58}$. Pero la realidad operativa es que en función de los flujos de energía, y especialmente cuando la generación local supera la demanda, las pérdidas de red podrían aumentar. Por ello, se hace necesaria la importación de esquemas regulatorios definidos en otros países europeos acerca de la participación empresas eléctricas en el coste de las pérdidas para el sistema eléctrico ${ }^{59}$; desapareciendo así la exclusiva participación solidaria de los consumidores en estas pérdidas.

Este nuevo modelo descentralizado también será reclamado por las Directivas 2010/31/UE del Parlamento Europeo y del Consejo, de 19 de mayo, relativa a la eficiencia energética de los edificios ${ }^{60}$ y 2012/27/UE del Parlamento Europeo y del Consejo, de 25 de octubre, relativa a la eficiencia energética ${ }^{61}$.

Además, como ya hemos subrayado, el autoconsumo emplea tecnologías que, gracias a los avances investigadores acontecidos en los últimos tiempos, han experimentado reducciones muy notables de sus costes. Se evidencia la superación de un

56 DOUE núm. 140, de 5 de junio de 2009.

57 Sobre los beneficios que reporta el autoconsumo de electricidad y otras implicaciones de éste en el actual escenario energético, Véase GONZÁLEZ RÍOS, I. "La incipiente regulación del autoconsumo de energía eléctrica: implicaciones energéticas, ambientales y urbanísticas", en Revista Vasca de Administración Pública, núms. 99-100 (2014), pp. 1638-1642; ORTIZ GARCÍA, M., "El marco jurídico de la generación distribuida de energía eléctrica: autoconsumo, redes inteligentes y el derecho al sol", en F. GARCÍA RUBIO. Y L. MELLADO RUIZ (dirs), Eficiencia energética y derecho, Ed. Dykinson, Madrid, 2013, pp. 235-286; y ORTIZ GARCÍA, M., "El autoconsumo eléctrico", en R. R. GALÁN VIOQUE, I. GONZÁLEZ RÍOS y F. LÓPEZ RAMÓN (dirs.), Derecho de las energías renovables y la eficiencia energética en el horizonte 2020, Ed. Thomson Reuters Aranzadi, Cizur Menor, 2017, pp. 267-297.

58 Véase. FABRA UTRAY, J. (2017), "El marco actual y potencial del sistema eléctrico español para la generación distribuida de electricidad", en Revista de Obras Públicas: Órgano profesional de los ingenieros de caminos, canales y puertos, núm. 3584 (2017), p. 21.

59 Sobre este punto se pronunció la CNMC en el "Informe sobre alternativas de regulación en materia de reducción de pérdidas y tratamiento del fraude en el suministro eléctrico" (PDN/DE/001/2015), de 16 de julio de 2015.

60 DOUE núm. 153, de 18 de junio de 2010.

61 DOUE núm. 315, de 14 de noviembre de 2012. 
escenario anterior donde los costes medios superaban en más de siete veces el de su alternativa convencional térmica (ciclos combinados de gas natural y centrales de carbón), lo que unido a los positivos retornos sociales, económicos y ambientales que la generación distribuida renovable reporta, aconseja la adopción de una regulación eléctrica más favorable ${ }^{62}$. Así, el autoconsumo colectivo aparece especialmente para dar cobertura a aquellos que no disponen de espacio suficiente para instalar tecnologías renovables para el autoconsumo (ej. paneles solares, pequeñas turbinas eólicas...), lo que reporta importantes beneficios económicos y sociales ${ }^{63}$.

En este orden de cosas, el Tribunal Constitucional, por medio de la Sentencia núm. 68/2017, de 25 de mayo ${ }^{64}$, se ha pronunciado acerca de la prohibición contenida en el artículo 4.3. RD 900/2015.

El Estado español, a través de la Abogacía del Estado, ha tratado de justificar la prohibición contenida en el precepto citado esgrimiendo que se trata de una mera concreción técnica de lo establecido en el artículo 39.3 LSE, el cual dispone que «Todas las instalaciones destinadas a más de un consumidor tendrán la consideración de red de distribución y deberán ser cedidas a la empresa distribuidora de la zona, la cual responderá de la seguridad y calidad de suministro. Dicha infraestructura quedará abierta al uso de terceros». Ello impediría la existencia de una red interior de varios consumidores.

A lo que el tribunal objeta que no tiene cabida considerar estas instalaciones como redes de distribución en la medida en que discurren por la red interior de varios consumidores y, por tanto, deben tener la consideración de «instalaciones de enlace», las cuales serán propiedad de los usuarios receptores que pudieran encontrarse en una misma urbanización o edificio. En otras palabras, no cabría afirmar que las instalaciones destinadas a más de un consumidor sean calificadas como redes de distribución abiertas al acceso de terceros, por lo que carece de sentido prohibir que varios consumidores reciban energía en su red interior procedente de un mismo centro de producción. Así, el TC decide anular el artículo 4.3 RD 900/2015, ya que no existen problemas técnicos que imposibiliten la construcción de un sistema único de energía eléctrica (por ej. un edificio o varios destinados a vivienda o uso comercial que pertenezcan a un mismo propietario) o de un sistema común de energía eléctrica

62 Vid. FABRA UTRAY, J. (2017: 25).

63 Acerca de los beneficios que supone el autoconsumo compartido, véase LARRAZA LÁZCOZ, A. "Autoconsumo compartido: por qué impulsarlo y cómo", en Revista de Obras Públicas: Órgano profesional de los ingenieros de caminos, canales y puertos, núm. 3584 (2017), pp. 56-65.

64 Sentencia del Pleno del Tribunal Constitucional sobre el conflicto positivo de competencias núm. 574-2016 interpuesto por el Consejo de Gobierno de la Generalitat de Cataluña en relación con diversos preceptos del RD 900/2015. BOE núm. 156, de 1 de julio de 2017. 
(por ej. en un edificio de viviendas, urbanizaciones o cualquier otro edificio complejo con distintos propietarios y elementos comunitarios).

Asimismo, el TG sostiene que esta prohibición no puede considerarse inmersa en las competencias del Estado, ya que no cabe apreciar que el contenido del 4.3 RD 900/2015, como es la pretensión de la Abogacía del Estado, cumpla con los requisitos materiales de la normativa básica sobre redes de distribución, los cuales están desarrollados ampliamente en la STC 18/2011, de 3 de marzo ${ }^{65}$. Por tanto, en la medida en que las instalaciones que discurren por la red interior de varios consumidores no pueden ser calificadas como redes de distribución, sino como instalaciones de enlace, la competencia para habilitar el autoconsumo colectivo y potenciar su uso en una región se atribuye a las Comunidades Autónomas.

Así pues, la propuesta de RD de acceso y conexión aborda la figura del autoconsumo colectivo y prevé la reforma de varios preceptos del RD 900/2015 a través de su disposición final segunda. Atendiendo, así, una nueva figura que previsiblemente se irá implantando de forma progresiva en nuestro país ${ }^{66}$.

En primer lugar, se define el autoconsumo colectivo, apto para todas las modalidades (tipo 1 y tipo 2), como la conexión de uno o varios generadores a la red interior de más de un consumidor ubicados en la misma referencia catastral (cuya identificación responde a los primeros catorce dígitos). También aparecen otros conceptos que pivotan en torno a la figura del autoconsumo colectivo, como son la demanda horaria individualizada, el autoconsumo horario individualizado y la energía horaria consumida individualizada.

65 Así, la sentencia dispone que, en materia de distribución, le corresponde al Estado "[...] la ordenación básica o primaria de la actividad para, entre otros objetivos, determinar las condiciones de tránsito de la energía eléctrica por dichas redes, establecer la suficiente igualdad entre quienes realizan la actividad en todo el territorio y fijar las condiciones equiparables para todos los usuarios de la energía eléctrica (artículo 39.3 LSE) [...]”; “[...] el establecimiento de los criterios de regulación de distribución de la energía eléctrica atendiendo a zonas eléctricas con características comunes y vinculadas con la configuración de la red de transporte y de ésta con las unidades de producción [...]"; y desarrollar una labor de coordinación "[...] con la que se persigue, en esencia, la integración de la diversidad de las partes del sistema en el conjunto del mismo mediante la adopción por el Estado de medios y sistemas de relación, para asegurar la información recíproca, la homogeneidad técnica en ciertos aspectos y la acción conjunta de las autoridades estatales y autonómicas en el ejercicio de sus respectivas competencias, todo ello con el fin de evitar contradicciones o reducir disfunciones que pudieran impedir o dificultar el funcionamiento del sistema [...]". Por lo que estos requisitos no concurren en el supuesto de las instalaciones de enlace a que se refiere el artículo 4.3 RD 900/2015.

66 Destacadamente la empresa Holaluz ha logrado la legalización de la primera instalación de autoconsumo compartido o colectivo en España. Se construyó con placas fotovoltaicas en un bloque de viviendas de Rubí, provincia de Barcelona. Véase http://www.diariorenovables.com/2018/08/holaluz-legaliza-la-primera-instalacion-autoconsumo-compartido-espana.html? $\mathrm{m}=1$. 
Por otro lado, se definen requisitos específicos para sujetos acogidos a la modalidad de tipo 1 y tipo 2 que realicen autoconsumo colectivo, los cuales vienen a completar los generales ya establecidos en el artículo 5 RD 900/2015 para acogerse a una modalidad de autoconsumo. Para esta modalidad se va a exigir de los titulares de instalaciones de producción que, en el marco del procedimiento de conexión y acceso, acrediten la autorización de todos los consumidores titulares de la red interior a la que estén conectados. También se establecerán requisitos específicos de medida para estas instalaciones, las cuales deberán disponer de equipos de medida bidireccional para calcular la energía neta generada y de equipos de medida que registren la energía consumida total por cada consumidor asociado.

Asimismo, se van a establecer los criterios para la determinación de componentes de la facturación de peajes de acceso ${ }^{67}$ y de los cargos asociados a los costes del sistema eléctrico ${ }^{68}$, los cuales vienen a completar los ya definidos con carácter general para las categorías de autoconsumo tipo 1 y 2.

\section{E. El registro autonómico para autoconsumidores}

El TG se pronunció sobre la constitucionalidad de los artículos 19 a 22 RD 900/2015 a través de la ya citada Sentencia núm. 68/2017. Estos preceptos definen un registro administrativo de carácter estatal al que deberán inscribirse (artículo 20), a través de un procedimiento establecido (artículo 21), todos los consumidores acogidos a cualquiera de las modalidades de autoconsumo. También se recogen las reglas para la modificación y cancelación de inscripciones (artículo 22).

Así, el TC, con apoyatura en su propia doctrina (SSTG 243/1994, de 21 de julio $^{69}$ y 197/1996, de 28 de noviembre ${ }^{70}$ ), sostiene que este registro excede el ámbito de competencias del Estado, pues la finalidad del mismo -el control y adecuado seguimiento de los autoconsumidores (artículo 19.3)- presenta carácter ejecutivo y, por tanto, entra en la esfera competencial autonómica.

67 Para la modalidad tipo 1 se aplicarán los siguientes criterios: «i) El control de la potencia contratada por cada consumidor se realizará sobre la potencia de cada uno de los consumidores utilizando a estos efectos el equipo que registra la energía horaria consumida individualizada; ii) Para la determinación del término de facturación de energía activa la energía a considerar será la demanda horaria individualizada; iii) para la determinación, en su caso, del término de facturación energía reactiva se utilizará el equipo que registra la energía horaria consumida individualizada».

Por otro lado, para la facturación de los peajes de acceso de la modalidad tipo 2 se atenderá a los criterios ya definidos con carácter general en el artículo 16.3 RD 900/2015.

68 Para la determinación de estos cargos de los sujetos que realicen autoconsumo colectivo en una misma referencia catastral, tanto en modalidad tipo 1 como tipo 2, se entenderá que: «i) La aplicación de cargos fijos se realizará sobre la potencia de aplicación de cargos de cada consumidor utilizando a estos efectos el equipo que registra la energía horaria consumida individualizada; ii) La aplicación de cargos variables se realizará sobre la energía horaria consumida individualizada».

69 BOE núm. 197, de 18 de agosto de 1994.

70 BOE núm. 3, de 3 de enero de 1997. 
La propuesta de RD de acceso y conexión, adecuándose a esta doctrina del TC, persigue habilitar a las CGAA para crear y gestionar los correspondientes registros territoriales de autoconsumo (artículos 19 a 21). Se mantiene el registro administrativo de autoconsumo de energía eléctrica del Ministerio de Energía, Turismo y Agenda Digital (MINETAD), el cual recibirá información de los registros autonómicos (artículo 19.2.a); debiendo inscribirse en este registro estatal aquellos autoconsumidores localizados en regiones donde no se haya creado registro autonómico (artículo 19.2.b).

Establece la obligación de inscripción de los autoconsumidores en los registros administrativos autonómicos, la cual se llevará a cabo siguiendo los hitos procedimentales definidos por la norma autonómica. Si bien se establecen unos hitos para la inscripción en el registro estatal para aquellos casos en que no exista norma en el territorio donde se realiza autoconsumo. Además, debe existir un intercambio de datos ágil y homogéneo entre CGAA y Estado por vía electrónica (artículo 20).

Por último, las propuestas de inscripción, modificación y cancelación que emitan las CCAA tendrán que ser aceptadas como vinculantes por el Estado. Las CCAA a comunicar a la Dirección General de Política Energética y Minas las altas, bajas y modificaciones que se hayan producido en sus registros. Así como también define un procedimiento para la modificación y cancelación de las inscripciones en el registro estatal en aquellos casos en que una instalación de autoconsumo de electricidad esté ubicada en un territorio en el que no exista registro administrativo de autoconsumo (artículo 22).

Por su parte, el Real Decreto-ley 15/2018 (artículo 18) se va a referir a un registro administrativo de autoconsumo de energía eléctrica del Ministerio para la Transición Ecológica. Disponiendo que las Comunidades Autónomas con competencia en la materia van a poder crear y gestionar sus propios registros territoriales. Ello va a suponer una modificación del contenido del artículo 9 LSE.

\section{CONCLUSIONES}

Primero. Las redes de electricidad deben asumir una importante función al servicio de los distintos operadores, en aras de lograr una economía descarbonizada y una mayor electrificación de la sociedad.

Así, el principio de ATR aparece como la piedra angular de la liberalización del sector eléctrico y persigue configurar un derecho universal de acceso de los distintos agentes a las redes de electricidad ajenas, en base a criterios de transparencia y no discriminación. Ello servirá de contrapunto al carácter monopolista que presenta la red, lo que va a favorecer la apertura del mercado eléctrico a nuevos operadores. 
Segundo. El acceso a las redes tiene que ver con la formación de un mercado eléctrico e implica el análisis de la zona de influencia, y, por tanto, excede del ámbito autonómico. Por este motivo la competencia en materia de resolución de conflictos es estatal. Mientras que la resolución de conflictos de conexión podría entrar en la esfera competencial de las Comunidades Autónomas, al encontrarse la conexión estrechamente relacionada con la seguridad de las instalaciones que se acoplan físicamente a un punto de la red que será objeto de análisis, salvo que la autorización de la infraestructura de red a la que se acopla el solicitante sea de competencia estatal.

En este contexto, el artículo 33.5 LSE, aún no vigente, va a requerir un informe previo vinculante de la GNMC para los casos de resolución de conflictos de conexión de competencia autonómica y cuando verse sobre condiciones económicas y temporales relativas a calendarios de ejecución de las instalaciones de los titulares de redes recogidas en la planificación de la red de transporte y en los planes de inversión de las empresas distribuidoras aprobados por la AGE. Este carácter vinculante ha suscitado cierta polémica en tanto podía suponer una injerencia en competencias ejecutivas autonómicas. Sin embargo, el TC ha interpretado favorablemente el precepto sobre la base del carácter estrictamente estatal que presentan la planificación de las redes y su régimen económico.

Finalmente, el ejecutivo ha incluido este informe vinculante en el artículo 17.3 propuesta RD de acceso y conexión.

Tercero. El ejecutivo, a través de la propuesta de reglamento de acceso y conexión, regula un régimen de renovación de derechos de acceso y conexión para atender la inminente caducidad de derechos de instalaciones de generación, anteriores a la entrada en vigor de la LSE de 2013, que tendrá lugar a finales de diciembre de 2018 (prorrogada a 2020). Se persigue así proteger a los operadores de un sector donde la continuidad de las inversiones se ha visto seriamente afectada por la crisis económica. Aunque cabría anotar que la técnica jurídica empleada para la configuración de estas renovaciones no es la más adecuada, pues se trata de una norma de rango inferior a la LSE. Asimismo, también sería deseable una mayor armonía entre la forma de cómputo prevista en la norma estatal para el cálculo de la caducidad de derechos de acceso y conexión y la propia definida en la norma autonómica para la caducidad de los procedimientos de autorización administrativa.

La renovación, por cinco años más, requerirá de la aportación de una garantía económica de mayor cuantía a la aportada en el procedimiento de obtención de derechos de acceso y conexión. En principio, esto debería erradicar los comportamientos especulativos que adoptan algunos agentes, mediante el bloqueo de capacidades, y que les permiten vender el punto de la red en un momento de alta demanda. 
Cuarto. La propuesta de Real Decreto de acceso y conexión define la figura del Interlocutor Único de Posición (IUP) con la finalidad de optimizar la utilización de las redes de transporte y distribución de electricidad, para aquellos casos en que varias instalaciones se ven obligadas a compartir infraestructuras de evacuación. Ahora el ámbito de actuación del interlocutor se reduce a la posición concreta del nudo al que se conectan las instalaciones de producción, lo que evita que esta figura tenga el control de la totalidad del nudo y pueda adoptar comportamientos abusivos.

Aunque la designación del IUP responde al acuerdo entre las partes, lo que minimiza posibles conflictos de interés, deviene necesaria una figura independiente sin intereses económicos particulares en el nudo con unas funciones y responsabilidades detalladas.

Todo ello es de capital importancia en la medida en que la capacidad de acceso y conexión disponible en las redes constituye un bien colectivo que no puede quebrantarse por actuaciones particulares de los distintos agentes interesados.

Quinto. El autoconsumo de electricidad supone un verdadero cambio en el modelo de generación de energía eléctrica que trae consigo la reducción de inversiones en nuevas redes, de pérdidas por el transporte y de emisiones de gases de efecto invernadero. Así, la transición de un modelo centralizado a uno distribuido por todo el territorio necesita de un marco regulatorio estable, que hasta la fecha ha brillado por su ausencia.

Con la propuesta de RD de acceso y conexión se camina hacia la simplificación de requisitos técnicos estableciendo exenciones de la obtención de permisos y un procedimiento abreviado de conexión de instalaciones para determinadas instalaciones.

Destacadamente, la propuesta, tras la anulación del artículo 4.3. RD 900/2015 (STC 68/2017), regula el autoconsumo colectivo para todas las modalidades de autoconsumo ya definidas. Específicamente, se definen requisitos de medida bidireccional y se establecen criterios para la determinación de componentes de la facturación de peajes de acceso y de los cargos asociados a los costes del sistema eléctrico.

También para ajustarse a lo dispuesto en la citada sentencia, el ejecutivo habilita a las Comunidades Autónomas para crear sus propios registros para autoconsumidores, los cuales enviarán información al registro estatal ya existente para lograr una intercambio de datos eficaz y homogéneo entre administraciones.

Sin embargo, no se observa un esquema de acceso y conexión compatible de forma efectiva con el desarrollo de redes de recarga para vehículos eléctricos. 


\section{BIBLIOGRAFÍA}

- ARIÑO ORTIZ, G., "Empresa pública versus regulación económica", en G. ARIÑO ORTIZ, I. DEL GUAYO CASTIELLA y J. M. DE LA CUÉTARA MARTÍNEZ (coords.), Regulación Económica. Lecturas Escogidas, Ed. Thomson Reuters Aranzadi, Cizur Menor, 2012.

-DE LA CRUZ FERRER, J., "El debate sobre el régimen jurídico del tendido de redes de distribución y de su acceso y conexión a otras redes", en Revista de derecho de las telecomunicaciones e infraestructuras en red, núm. 20 (2004).

- DEL GUAYO CASTIELLA, I., "Energy Law in Spain. Energy Networks", en M. ROGGENKAMP, C. REDGWELL, A. RØNNE, E I. DEL GUAYO CASTIELLA (eds), Energy Law In Europe (National, EU and International Regulation), Third Edition, Ed. Oxford University Press, Oxford, 2016.

-DEL GUAYO CASTIELLA, I. "La Comisión Nacional de los Mercados y la Competencia y la resolución de conflictos en el sector energético", en F. LÓPEZ RAMÓN (coord.), Las vías administrativas de recurso a debate, Ed. INAP, Madrid, 2016.

-DIATHESOPOULOS, M. D., "Access to European Energy Networks: The Relation between Third Party Access and Refusal to Deal Concepts", in Social Science Research Network (posted: 02 Jan 2011).

-ESTOA PÉREZ, A., "Acceso a redes de energía eléctrica, resolución de conflictos y evolución normativa en la materia", en Revista General de Derecho Administrativo, núm. 43 (2016).

-FABRA UTRAY, J., "El marco actual y potencial del sistema eléctrico español para la generación distribuida de electricidad", en Revista de Obras Públicas: Órgano profesional de los ingenieros de caminos, canales y puertos, núm. 3584 (2017).

-GERARD, H., RIVERO PUENTE, E. I. y SIX, D., "Coordination between transmission and distribution system operators in the electricity sector: A conceptual framework", en Utilities Policy, 2018.

-GONZÁLEZ RÍOS, I., "La incipiente regulación del autoconsumo de energía eléctrica: implicaciones energéticas, ambientales y urbanísticas", en Revista Vasca de Administración Pública, núm. 99-100 (2014).

-HANCHER, L. and WINTERS, M., The EU Winter Package, Briefing Paper, Allen \& Overy LLP, Amsterdam, 2017.

-KAZIMIERSKI, M. A., "Almacenamiento energético frente al inminente paradigma renovable: el rol de las baterías ion-litio y las perspectivas sudamericanas”, en Letras Verdes, núm. 23 (2018). 
-LARRAZA LÁZCOZ, A., "Autoconsumo compartido: por qué impulsarlo y cómo", en Revista de Obras Públicas: Órgano profesional de los ingenieros de caminos, canales y puertos, núm. 3584 (2017).

-LAVRIJSSEN, S. y KOHLBACHER, T., "EU Electricity Network Codes: Good Governance in a Network of Networks", en Tilburg Law and Economics Center (TILEC) Discussion Paper, núm. 2018-001.

-LEIVA LÓPEZ, A. D., "La regulación del autoconsumo de electricidad en un nuevo entorno social y tecnológico", en Revista Vasca de Administración Pública, núm. 110, tomo 1 (2018a).

-LEIVA LÓPEZ, A. D., «La regulación de la actividad de distribución de energía eléctrica», en Revista Aragonesa de Administración Pública, núm. 51 (2018b)

-MENDOZA LOSANA, A. I., "Régimen retributivo de las instalaciones de energías renovables tras la celebración de las últimas subastas de potencia renovable en España”, en Análisis jurídicos GA\&P(2017), Gómez-Acebo \& Pombo.

-ORTIZ GARCÍA, M., "El autoconsumo de electricidad en España y su (primera) ordenación jurídica. Un avance (lento) hacia el imparable cambio de modelo energético", en I. REVUELTA PÉREZ (dir.), La regulación de las energías renovables a la luz del Derecho de la Unión Europea, Ed. Thomson Reuters Aranzadi, Cizur Menor, 2017.

-ORTIZ GARCÍA, M. "El autoconsumo eléctrico", en R. R. GALÁN VIOQUE, I. GONZÁLEZ RÍOS y F. LÓPEZ RAMÓN (dirs.), Derecho de las energías renovables y la eficiencia energética en el horizonte 2020, Ed. Thomson Reuters Aranzadi, Cizur Menor, 2017.

-ORTIZ GARCíA, M., "El marco jurídico de la generación distribuida de energía eléctrica: autoconsumo, redes inteligentes y el derecho al sol", en F. GARCÍA RUBIO y l. MELLADO RUIZ (dirs.), Eficiencia energética y derecho, Ed. Dykinson, Madrid, 2013.

-TORRES LÓPEZ, M. A., "El derecho de acceso de terceros a las redes de transporte y distribución de electricidad (Comentario a la STJCE, Sala $3^{\text {a }}$, de 9 de octubre de 2008, As. C-239/07)", en Noticias de la Unión Europea, núm. 312 (2011).

-YEMANE HADUSH, S. y MEEUS, L., "DSO-TSO cooperation issues and solutions for distribution grid congestion management”, en Energy Policy, 2018. 